\title{
Comparative Growth, Morphology, and Anatomy of Easy- and Difficult-to-acclimatize Sea Oats (Uniola paniculata) Genotypes During In Vitro Culture and Ex Vitro Acclimatization
}

\author{
Carmen Valero Aracama, Michael E. Kane, Sandra B. Wilson ${ }^{1,2}$, and Nancy L. Philman \\ Department of Environmental Horticulture, University of Florida-IFAS, Gainesville, FL 32611
}

\begin{abstract}
ADDITIONAL INDEX WORDS. micropropagation, native grass, transmission electron microscopy, leaf histology, dune restoration
Abstract. Growth and development of two sea oats (Uniola paniculata L.) genotypes with differing acclimatization capacities when transferred from in vitro to ex vitro greenhouse conditions were compared as a function of the duration of shoot multiplication and rooting stages. Anatomical and morphological development differed between genotypes in vitro. After 4, 8, and 12 weeks of Stage II culture, leaf length and shoot number were significantly greater for the easy-to-acclimatize genotype (EK 16-3) than the difficult-to-acclimatize genotype (EK 11-1). Shoot dry weights in both genotypes were greatest after 4 weeks culture. Browning and dying of tissue steadily increased with time. Shoot number per plantlet increased from Week 4 to 8 in both genotypes but decreased after 12 weeks. Once transferred to Stage III culture for 6 weeks, significant differences in root architecture and morphology were observed between the two genotypes. EK 16-3 plantlets developed short but numerous roots and "grass-like" leaves with fully expanded blades. Conversely, EK 11-1 plantlets developed few long roots and "lance-like" leaves, which were short, thick, and without expanded blades. Anatomical and morphological development during Stage III differed between culture duration and genotypes. Shoot and root dry weights of both genotypes increased during 3, 6 , and 9 weeks of culture. Shoot dry weights of EK 16-3 plantlets were lower at 3 weeks but higher at 9 weeks than EK 11-1. Conversely, root dry weights were higher for EK 11-1 than for EK 16-3 plantlets throughout Stage III culture. Anatomical observations of EK 11-1 plantlets using light and electron microscopy correlated poor ex vitro acclimatization and poor survival with abnormal tissue organization, stomatal aperture blockage, and thylakoid membrane disruption.
\end{abstract}

Sea oats is a perennial dune grass native to the southeastern United States. This species is commonly used for beach restoration and dune stabilization in Florida after dune systems are damaged or destroyed by tropical storms or human activity (Bachman and Whitwell, 1995). Sea oats has the ability to rapidly establish and colonize and exhibits high tolerance to heat, drought, and salinity (Woodhouse, 1982). The root and rhizome systems hold sand particles together, whereas the vegetation aboveground retards wind and water-driven erosion and promotes sand deposition (Woodhouse, 1982).

Sea oats is propagated under nursery conditions from fieldcollected seeds. However, seed sources have become limited as a result of storm damage to seed donor populations. Moreover, state and federal policies limit the use of seeds and/or plant materials obtained from distant geographic sources to minimize the introduction of unadapted ecotypes to revegetation sites. These policies have negatively impacted the capacity for nurseries to meet the demand for plants. Consequently, alternative propagation methods, including micropropagation, have

\footnotetext{
Received for publication 12 June 2008. Accepted for publication 4 Sept. 2008. UF Indian River Research and Education Center Journal Series No. R-060801. This project was developed under the guidance of the Florida Sea Grant College Program and funded from NOAA, Department of Commerce, Grant No. NA16RG-2195.

We thank Ramon Littell for his statistical expertise and Karen Kelley and Fred Bennett for their technical assistance with the histological studies.

${ }^{1}$ Current address: Indian River Research and Education Center, University of Florida-IFAS, Department of Environmental Horticulture, 2199 South Rock Road, Fort Pierce, FL 34945.

${ }^{2}$ Corresponding author. E-mail: sbwilson@ufl.edu.
}

been developed for mass production of sea oats plant genotypes to complement seed propagation from local populations.

A micropropagation protocol for sea oats was developed by Philman and Kane (1994). Additionally, 28 different sea oats genotypes were established, multiplied, and rooted using this protocol. However, significant differences in survival and acclimatization capacity were observed among genotypes when plants were transferred to ex vitro conditions. Similarly, many other horticultural plants species are readily micropropagated in vitro but exhibit poor acclimatization and subsequent survival ex vitro (Debergh and Zimmerman, 1991). Alterations in the morphological and anatomical characteristics of plants during and after in vitro culture appear to play a critical role in successful acclimatization to greenhouse conditions (Serret and Trillas, 2000). In sea oats, a better understanding of the morphological, anatomical, and physiological bases for differences in acclimatization between genotypes is required to develop more efficient micropropagation procedures.

The environmental conditions in vitro compromise plantlets' leaf morphology, epicuticular and cuticular wax formation, stomata functioning, chlorophyll content, leaf blade expansion, stomatal density, spongy and palisade tissue differentiation (Kozai et al., 1992), photosynthetic capacity (Grout and Aston, 1978), and dry matter accumulation (Ziv, 1991). Often, these characteristics negatively impact the capacity for ex vitro acclimatization, but the degree to which plants are affected by the in vitro environment depends on the plant species. Furthermore, genotypic differences within species during in vitro propagation have also been reported (Llorente and Apóstolo, 1998). The extent of the differences in acclimatization capacity between in vitro-propagated sea oats genotypes 
is unclear. The overall objective of this study was to compare the anatomical and morphological development of easy- and difficult-to-acclimatize sea oats genotypes as affected by in vitro multiplication (Stage II) and rooting (Stage III) conditions. Specific objectives were to 1) assess the effect of Stage II and Stage III duration on in vitro growth and rooting and ex vitro (Stage IV) survival; and 2) correlate leaf anatomy, stomatal development, and chloroplast ultrastructure of in vitro and ex vitro-grown sea oats genotypes having differing capacities for acclimatization.

\section{Materials and Methods}

Plant material and culture conditions. Established, stabilized, and indexed cultures of $U$. paniculata, genotyped using random amplified polymorphic DNA genetic analyses (Ranamukhaarachchi, 2000), and previously characterized (Valero-Aracama et al., 2006) as easy- and difficult-toacclimatize (EK 16-3 and EK 11-1, respectively) were used in this study. Five sea oats shoot clusters (each consisting of three shoots, $25 \mathrm{~cm}$ long) of EK 16-3 and EK 11-1 genotypes were subcultured in $80 \mathrm{~mL}$ sterile Stage II medium into separate Magenta GA7 vessels (Magenta Corp., Chicago, IL). Medium consisted of Murashige and Skoog (MS) inorganic salts (Murashige and Skoog, 1962) supplemented with $87.6 \mathrm{~mm}$ sucrose, $0.56 \mathrm{~mm}$ myoinositol, $1.2 \mu \mathrm{M}$ thiamine-HCl, $2.2 \mu \mathrm{M}$ $\mathrm{N}^{6}$-benzyladenine (BA), and solidified with $8 \mathrm{~g} \cdot \mathrm{L}^{-1} \mathrm{TC}^{\mathrm{TM}}$ agar (PhytoTechnology Laboratories, Shawnee Mission, KS). The medium was adjusted to $\mathrm{pH} 5.7$ with $0.1 \mathrm{~N} \mathrm{KOH}$ before the addition of agar and autoclaving at $103.9 \mathrm{kPa}$ and $121^{\circ} \mathrm{C}$ for 21 min. Cultures were maintained for 8 weeks in a growth chamber at $24 \pm 1{ }^{\circ} \mathrm{C}, 58 \pm 5 \%$ relative humidity, 16-h photoperiod provided by cool-white fluorescent lamps (F20WT12.CW; General Electric, Fairfield, CT), and at $40 \pm$ $5 \mu \mathrm{mol} \cdot \mathrm{m}^{-2} \cdot \mathrm{s}^{-1}$ photosynthetic photon flux $(P P F)$ as measured at culture level. Subsequently, 25-mm long single shoots from each genotype were excised and transferred to Stage III rooting medium.

Stage III rooting basal medium consisted of $80 \mathrm{~mL}$ sterile half-strength MS medium, supplemented with $0.56 \mathrm{~mm}$ myoinositol, $1.2 \mu \mathrm{M}$ thiamine- $\mathrm{HCl}, 87.6 \mathrm{~mm}$ sucrose, and $10 \mu \mathrm{M} \alpha-$ naphthalene acetic acid, and adjusted to $\mathrm{pH} 5.7$ with $0.1 \mathrm{~N}$ $\mathrm{KOH}$. Medium was solidified with $8 \mathrm{~g} \cdot \mathrm{L}^{-1} \mathrm{TC}^{\mathrm{TM}}$ agar and autoclaved at $1.2 \mathrm{~kg} \cdot \mathrm{cm}^{-2}$ and $121{ }^{\circ} \mathrm{C}$ for $21 \mathrm{~min}$. Each GA7 culture vessel contained eight single microcuttings and were maintained in a culture room at $22 \pm 2{ }^{\circ} \mathrm{C}$ air temperature, 16-h photoperiod provided by cool-white fluorescent lamps (F96T12.CW.WM; General Electric), and $100 \pm 5$ $\mu \mathrm{mol} \cdot \mathrm{m}^{-2} \cdot \mathrm{s}^{-1} P P F$ measured with a light sensor (model QMSWSS; Apogee Instruments, Roseville, CA) as measured at culture level.

Microcuttings were transferred to Stage IV conditions into 48-cell trays (eight six-celled blocks, each cell $4 \times 6 \times 5.5 \mathrm{~cm}$; T.O. Plastics, Clearwater, MN) containing coarse vermiculite as supporting material. Plug trays were placed in a greenhouse under controlled environmental conditions with a computercontrolled pad and fan cooling. The heating system used natural gas and was also computer-controlled. Plantlets were handwatered as needed and fertilized weekly at $150 \mathrm{mg} \cdot \mathrm{L}^{-1}$ nitrogen using 20N-8.7P-16.7K liquid fertilizer (Peters; Scotts, Marysville, $\mathrm{OH})$ prepared with the same source of water as used for watering.
Effect of Stage II duration on in Vitro multiplication AND ROOTING AND EX VITRo SURVIVAL. Plantlets from EK 11-1 and EK 16-3 produced using the protocol described previously were used in this experiment. Plantlets consisting of clusters of three shoots each were cultured for 4, 8, and 12 weeks under Stage II conditions. Number of shoots, number of leaves per shoot, leaf length, and dry weight of plantlets from five replicate vessels per genotype were measured after each culture period. Yield of microcuttings was evaluated considering shoots greater than $25 \mathrm{~mm}$ as harvestable microcuttings. A completely randomized design was used. This experiment was replicated once in time and because means were nonsignificantly different, pooled means are presented.

After plantlets of both genotypes were cultured for 4, 8, and 12 weeks Stage II, 64 microcuttings of each genotype were transferred to Stage III rooting medium in vessels arranged in a completely randomized design. Percent microcutting rooting was evaluated after 6 weeks in Stage III. Subsequently, 48 microcuttings were transferred to Stage IV conditions and percent survival was determined after 4 weeks ex vitro culture. Stage IV microcuttings were maintained in a greenhouse in Gainesville, FL, from 8 Aug. 2002 until 12 Dec. 2002 at 25/22.5 $\pm 2{ }^{\circ} \mathrm{C}$ day/night temperature and 700 to $1200 \mu \mathrm{mol} \cdot \mathrm{m}^{-2} \cdot \mathrm{s}^{-1} \mathrm{PPF}$ measured over the substrate level. The experiment was replicated once in time using the same greenhouse and time of the year and because means were nonsignificantly different, pooled means are presented.

Effect of Stage III duration on in vitro rooting, GROWTH, AND DEVELOPMENT AND EX VITRO SURVIVAL. EK 11-1 and EK 16-3 plantlets were cultured for 8 weeks under Stage II conditions following the protocol described previously. Subsequently, single shoots of each genotype were excised and then transferred to Stage III conditions for 3, 6, or 9 weeks in eight replicate vessels per treatment and time interval, each vessel containing eight shoots. At the conclusion of Stage III culture, two rooted plantlets per vessel were randomly selected to determine shoot number, leaf number per plant, leaf length, root number, root length, and dry weight of shoots and roots per plantlet. The remaining six plantlets per vessel were transferred to Stage IV conditions into the greenhouse. The same growth measurements of two plants per six-celled pack were obtained after 4 weeks ex vitro culture. Microcuttings were maintained at $25 / 22.5 \pm 2{ }^{\circ} \mathrm{C}$ (day/night temperature) for 6 weeks between 12 June and 24 July 2003 in a greenhouse in Gainesville, FL, with light intensities ranging from 700 to $1000 \mu \mathrm{mol} \cdot \mathrm{m}^{-2} \cdot \mathrm{s}^{-1}$ measured at the substrate level. This experiment was replicated once in time and plants were transferred ex vitro between 2 Aug. and 13 Sept. 2003.

Anatomical Comparisons. Leaf histological cross-sections were made from EK 11-1 and EK 16-3 microcuttings cultured in vitro in Stage II and Stage III following the protocols described previously and ex vitro in Stage IV. For optical light microscopy (OLM) and transmission electron microscopy (TEM), leaf sections $\approx 2 \mathrm{~mm}$ from the center of the leaf blade were fixed in Trumps fixative solution (McDowell and Trump, 1976). Fixative tissue infiltration was achieved under vacuum for $2 \mathrm{~d}$. Leaf tissues were then rinsed three times in phosphate buffer ( $\mathrm{pH} 7.2$ ), postfixed in a 1\% buffered osmium tetroxide solution, and then were rinsed in phosphate buffer, three times in distilled water, and dehydrated in a five-step $(25 \%, 50 \%$, $75 \%, 95 \%, 100 \%$ ) ascending ethyl alcohol series followed by dehydration in $100 \%$ acetone. An en bloc stain of $2 \%$ uranyl 
acetate was applied between the $75 \%$ and $95 \%$ steps of the ethyl alcohol dehydration series. Leaf sections were then embedded in Spurr resin (Spurr, 1969). For OLM, thick leaf sections (500 $\mathrm{nm}$ ) were obtained with a Leica Ultracut ultramicrotome R (Leica Microscopy and Scientific Instruments, Deerfield, IL) and then collected on glass slides. Sections were stained with $0.2 \%$ toluidine blue and examined using an Olympus BH-2 Epifluorescent Microscope (Olympus America, Melville, NY). Photographs were taken using a digital camera attachment (120C; Pixera Corp., Los Gatos, CA). Images are shown with adaxial side on top. For TEM, ultrathin leaf sections $(70 \mathrm{~nm})$ were cut from the center part of the leaf blade with a Leica Ultracut ultramicrotome R, collected on $0.35 \%$ form-varcoated copper grids, and stained with methanolic uranyl acetate and lead citrate (Reynolds, 1963). Sections were viewed on an electron microscope (H-7000; Hitachi Scientific Instruments, Danbury, CT) at $75 \mathrm{kV}$.

For scanning electron microscopy (SEM), leaf sections of $\approx 5 \mathrm{~mm}$ from the center of the leaf blade were immersed in
$100 \%$ methanol. Leaf tissues were collected from cultures $2 \mathrm{~h}$ after the photoperiod started and from cultures after a 5-h dark period. Sections were lyophilized using a Bal-Tec 030 critical point drier (ICMAS, Alcoa, TN) with liquid $\mathrm{CO}_{2}$, sputter-coated with gold-palladium using a Denton Vacuum Desk II (Denton Vacuum, Moorestown, NJ) for $\approx 50$ $\mathrm{s}$, and viewed with a SEM (S-4000 FS; Hitachi Scientific Instruments) operating at $6 \mathrm{kV}$. Digital images were processed using SEMages 16 software (Advance Database Systems, Denver, CO).

Statistical analysis. Percent data were subjected to arcsine transformation, and the significant differences among means were determined by two-way analysis of variance using the GLM procedure of SAS (version 8.02; SAS Institute, Cary, NC). Interactions among genotypes and time are presented in the tables and graphs. Separate a posteriori tests for significant differences among or between means were made using the Waller-Duncan procedure at $P=0.05$.

Table 1. Shoot number, leaf number, leaf length, and shoot dry weight of EK 11-1 and EK 16-3 sea oats genotypes after 4, 8, and 12 weeks Stage II culture.

\begin{tabular}{|c|c|c|c|c|c|c|c|c|c|c|c|}
\hline \multirow{2}{*}{$\begin{array}{l}\text { Stage II duration } \\
\text { (weeks) }\end{array}$} & \multicolumn{2}{|c|}{ Shoots (no.) ${ }^{\mathrm{z}}$} & \multirow[b]{2}{*}{$\bar{\chi}^{y}$} & \multicolumn{2}{|c|}{ Leaves (no.) } & \multirow[b]{2}{*}{$\bar{\chi}$} & \multicolumn{2}{|c|}{ Leaf length (mm) } & \multicolumn{3}{|c|}{ Shoot dry wt (mg) } \\
\hline & EK 11-1 & EK 16-3 & & EK 11-1 & EK 16-3 & & EK 11-1 & EK 16-3 & EK 11-1 & EK 16-3 & $\bar{\chi}$ \\
\hline 8 & 16.2 & 17.3 & $16.8 \mathrm{a}$ & 92.4 & 81.7 & $87.1 \mathrm{~b}$ & $8.8 \mathrm{~b}$ & $16.5 \mathrm{~b}$ & 157.0 & 162.6 & $159.8 \mathrm{~b}$ \\
\hline $\bar{\chi}$ & $14.2 \mathrm{~B}$ & $15.9 \mathrm{~A}$ & & & & & & & & & \\
\hline Analysis of variance ${ }^{x}$ & & & & & & & & & & & \\
\hline Genotype (G) & \multicolumn{2}{|c|}{$*$} & & \multicolumn{2}{|c|}{ NS } & & \multicolumn{2}{|c|}{$* *$} & \multicolumn{3}{|c|}{ NS } \\
\hline
\end{tabular}

${ }^{\mathrm{z}}$ Means followed by different letters under each growth parameter are significantly different according to Waller-Duncan test at $P \leq 0.05$. ${ }^{y}$ When no interaction was observed, means followed by lowercase letters indicate significant differences with Stage II duration. Means followed by uppercase letters indicate significant differences between genotypes.

x*,**, NS: Significant at $P=0.05$ or 0.01 and nonsignificantly different, respectively $(\mathrm{n}=16)$.

Table 2. Shoot and root growth parameters of EK 11-1 and EK 16-3 sea oats genotypes after 3, 6, and 9 weeks Stage III culture.

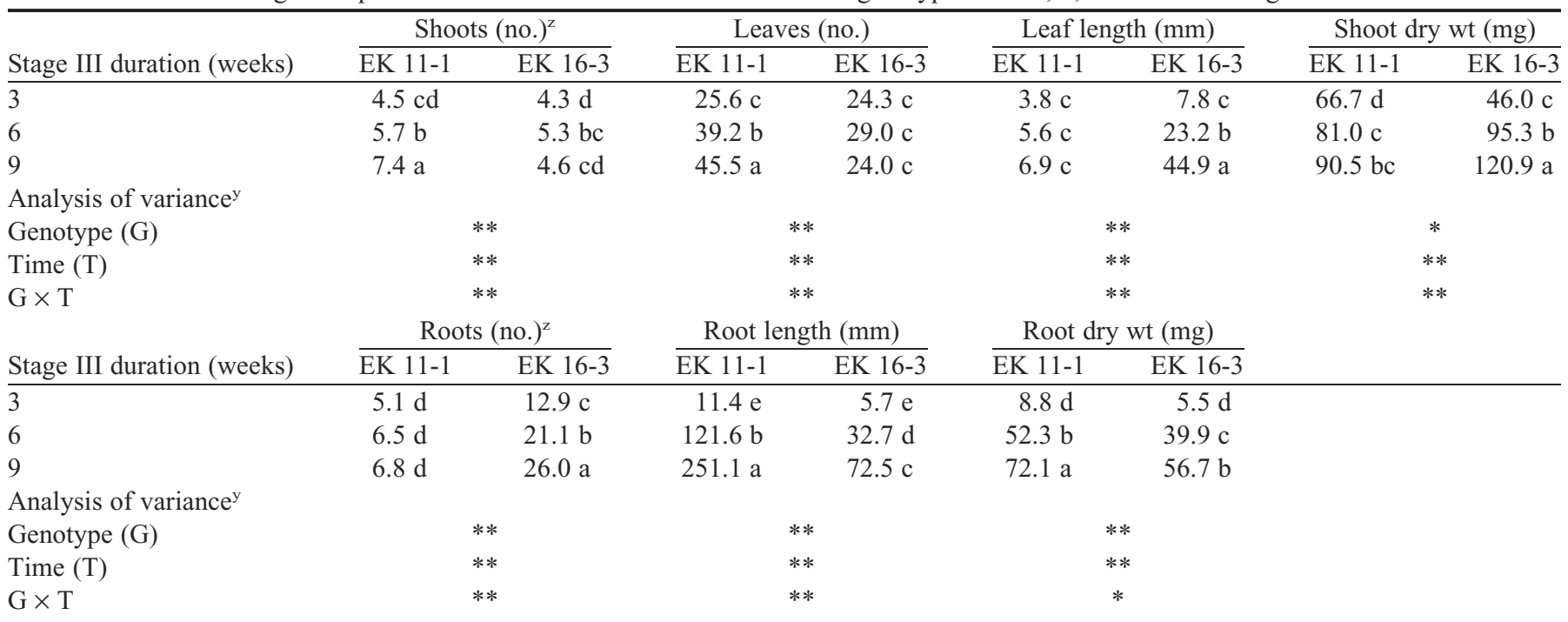

${ }^{\mathrm{z}}$ Means followed by different letters for each growth parameter are significantly different according to Waller-Duncan test at $P \leq 0.05$.

y*, **: Significant at $P=0.05$ or 0.01 , respectively $(\mathrm{n}=32)$. 


\section{Results}

Effect of Stage II duration on in vitro shoot growth and rooting and ex vitro survival

After 4 weeks Stage II culture, EK 11-1 and EK 16-3 sea oats genotypes had similar shoot dry weight and leaf elongation development (Table 1). Shoot multiplication at 4 weeks was slightly higher for EK 16-3 than for EK 11-1 plantlets. At 8 weeks Stage II, both genotypes exhibited browning of shoots and leaves, which continued to 12 weeks culture. At that time, most of the longest shoots had browned and only the newly developed shoots remained green in either genotype. Shoot dry weights in both genotypes were greatest at 4 weeks culture. Browning and dying of tissue steadily increased with time, and shoot number per plantlet increased from Week 4 to 8 in both genotypes but decreased after 12 weeks (Table 1). Similarly, leaf number decreased during Stage II culture in both genotypes resulting from leaf senescence and was greater in EK 11-1 than in EK 16-3 plantlets after 8 weeks' culture. Leaf length was $1.4,1.9$, and 1.2 times higher for EK 16-3 than EK 11-1 plantlets after 4, 8, and 12 Stage II, respectively. As time in vitro progressed, leaf length decreased in both genotypes (Table 1). The longest leaves, which were also the oldest, died and the newly formed leaves were considerably shorter. Relative leaf length frequencies indicated a larger occurrence of longer leaves in EK 16-3 than EK 11-1 plantlets throughout Stage II culture (data not presented).

Significant differences in root architecture and morphology were observed between the two genotypes after 4, 8, and 12 weeks Stage II culture after 6 weeks Stage III culture (data not presented). Stage III rooting was 100\% (regardless of Stage II duration) in EK 16-3 plantlets. This was significantly greater $(P=0.0136)$ than EK 11-1 plantlets having 93\%, 86\%, and 99\% rooting at 4,8 , and 12 weeks Stage II, respectively. Stage IV survivability was nearly $100 \%$ (regardless of Stage II duration) in EK 16-3 plantlets. This was significantly greater $(P<0.0001)$ than EK 11-1 plantlets having 30\%, 54\%, and 64\% survivability at 4,8 , and 12 weeks Stage II, respectively. Based on overall shoot growth, rooting, and survival after 4, 8, or 12 weeks Stage II culture, it was determined that microcutting quality was optimal at 8 weeks Stage II.

\section{Effect of Stage III duration on in vitro shoot growth and rooting and ex vitro survival}

Although EK 11-1 shoot number increased with time in Stage III, EK 16-3 shoot number progressively decreased (Table 2; Fig. 1). Significantly higher numbers of leaves were produced by EK 11-1 plantlets by Week 6 than by EK 16-3 plantlets throughout Stage III (Table 2). Conversely, by Week 6, leaves were four times longer in EK 16-3 than EK 11-1 plantlets and elongated rapidly, becoming 6.5 times longer in EK 16-3 than EK 11-1 plantlets by 9 weeks Stage III. Leaf length distributions indicated that leaf elongation was significantly inhibited in EK 11-1 (data not presented). Ninety-five percent of the EK 11-1 leaves were $15 \mathrm{~mm}$ long or less by 9 weeks' culture in contrast with EK 16-3, which produced $50 \%$ of leaves $16 \mathrm{~mm}$ long or greater.

Stage III root development differed significantly between genotypes. Root production, at each culture interval, was higher in EK 16-3 than EK 11-1 plantlets (Table 2). Conversely, EK
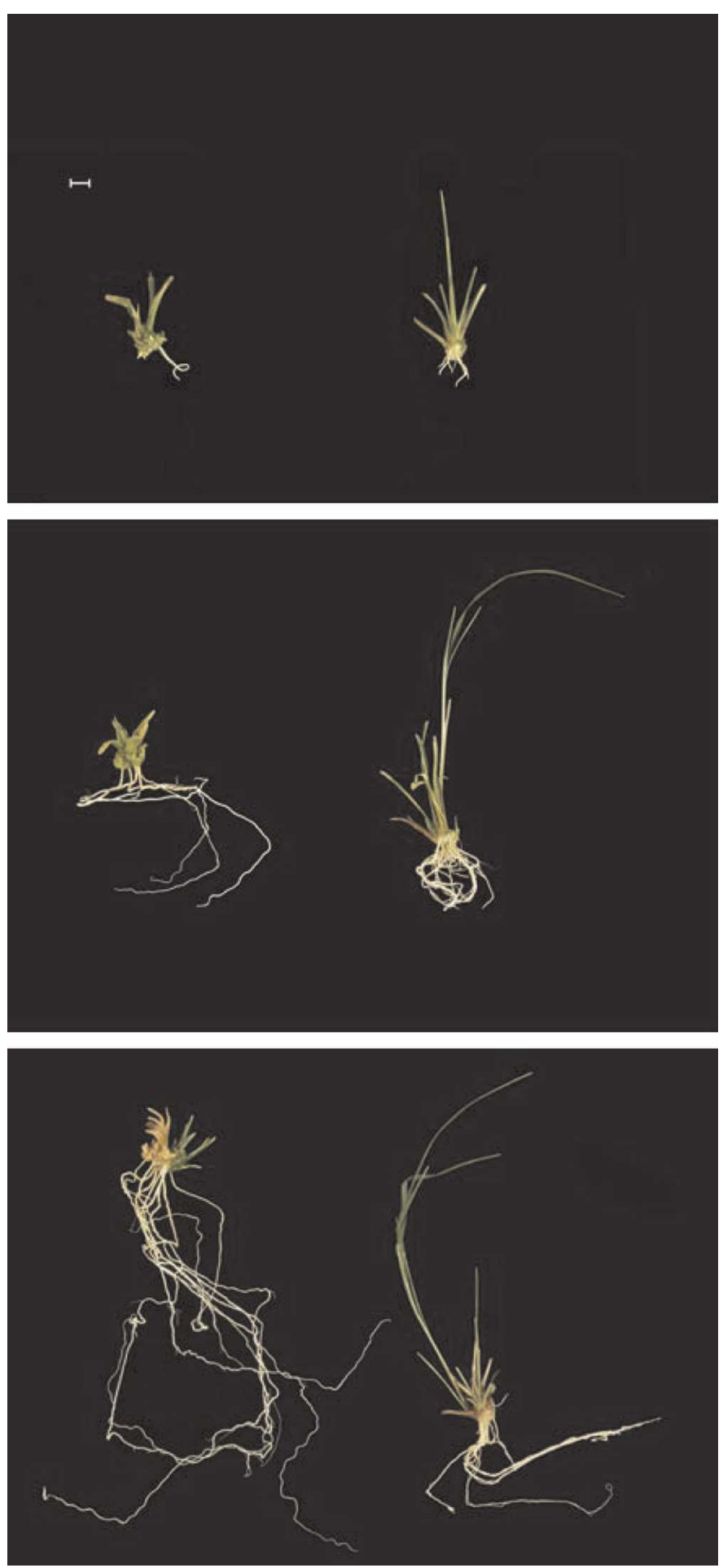

Fig. 1. Comparative morphological differences in rooting and shoot multiplication of EK 11-1 (left) and EK 16-3 (right) sea oats genotypes after 8 weeks Stage II followed by 3, 6, and 9 weeks Stage III culture (from top to bottom, respectively). Scale $=1 \mathrm{~cm}$.

11-1 roots were longer than EK 16-3 roots by Week 6 Stage III culture (Table 2; Fig. 1). Root length distributions indicated that EK 11-1 plantlets produced a greater percentage of longer roots than EK 16-3 plantlets from Week 3 and continued elongating until $50 \%$ of the roots ranged from 243 to $550 \mathrm{~mm}$ in length (data not presented). 
Shoot and root dry weights of both genotypes increased throughout Stage III culture (Table 2). At 3 weeks, shoot dry weights in EK 16-3 plantlets were lower than in EK 11-1 plantlets. However, at 6 and 9 weeks, shoot dry weights in EK 16-3 were greater than in EK 11-1 plantlets. Conversely, root dry weights were higher for EK 11-1 than for EK 16-3 plantlets after 6 weeks Stage III culture (Table 2). Shoot-to-root dry weight ratios were not significantly different between genotypes regardless of Stage III culture duration (data not shown).

Shoot and root dry weights after 4 weeks Stage IV increased in both genotypes with Stage III duration (Fig. 2A-B).

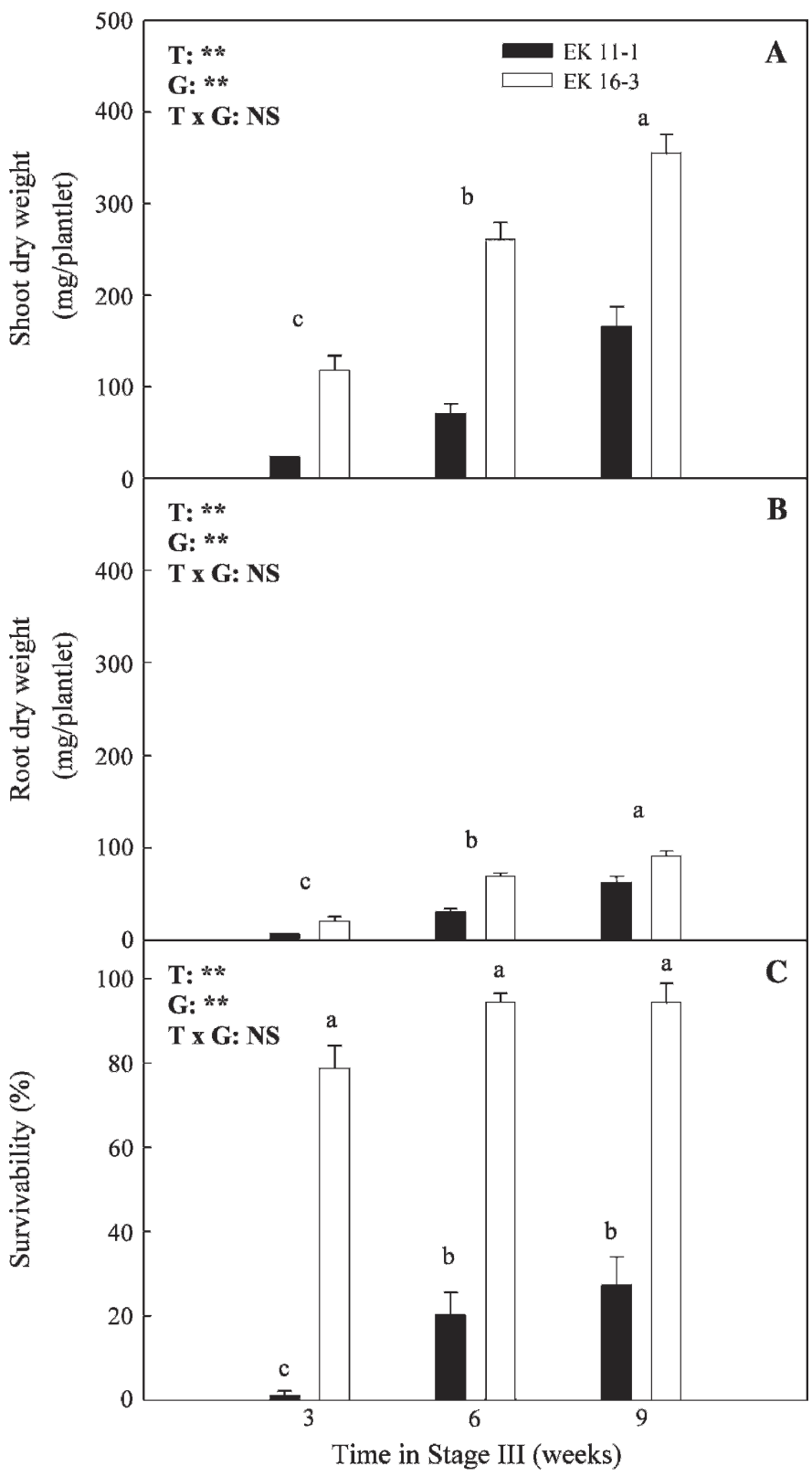

Fig. 2. Comparative ex vitro shoot dry weight (A), root dry weight (B), and survivability $(\mathbf{C})$ of sea oats genotypes after 3,6 , and 9 weeks Stage III culture followed by 4 weeks Stage IV culture. Error bars indicate SE. Analysis of variance is shown on top left corner of each graph; $\mathrm{T}=$ time, $\mathrm{G}=$ genotype. NS, ** nonsignificantly or significantly different at $P=0.01$, respectively. Different letters on top of histobars within each culture stage are significantly different with time according to Waller-Duncan test at $P \leq 0.05$.
Additionally, EK 16-3 plantlets exhibited greater shoot and root dry weights ex vitro than EK 11-1 regardless of Stage III duration (Fig. 2A-B). Stage III duration had a significant effect on ex vitro Stage IV survival of sea oats genotypes, especially in EK 11-1 plantlets (Fig. 2C). After 4 weeks Stage IV, survivability was $78 \%, 94 \%$, and $94 \%$ for EK $16-3$ and $1 \%$, $20 \%$, and $27 \%$ for EK 11-1 after 3, 6, and 9 weeks Stage III culture, respectively (Fig. 2C).

\section{Anatomical and ultrastructural comparisons}

OPTICAL LIGHT MICROSCOPY. Leaf sections collected from mature greenhouse plants of both genotypes cultured in vermiculite under the same greenhouse conditions as the ex vitro-transferred plants served as the reference (Fig. 3) for leaf development comparisons of plantlets in vitro (Figs. 4 and 5). The anatomy of ex vitro sea oats leaves was typical of $\mathrm{C}_{4}$ plants and was very similar between EK 11-1 and EK 16-3 genotypes (Fig. 3). Both genotypes possessed a compacted mesophyll composed of few large cells with most visible chloroplasts present in cells surrounding the vascular bundle. Additionally, they exhibited extensive vascular bundles that were oval in shape and occupied most of the leaf cross-section (Fig. 3).
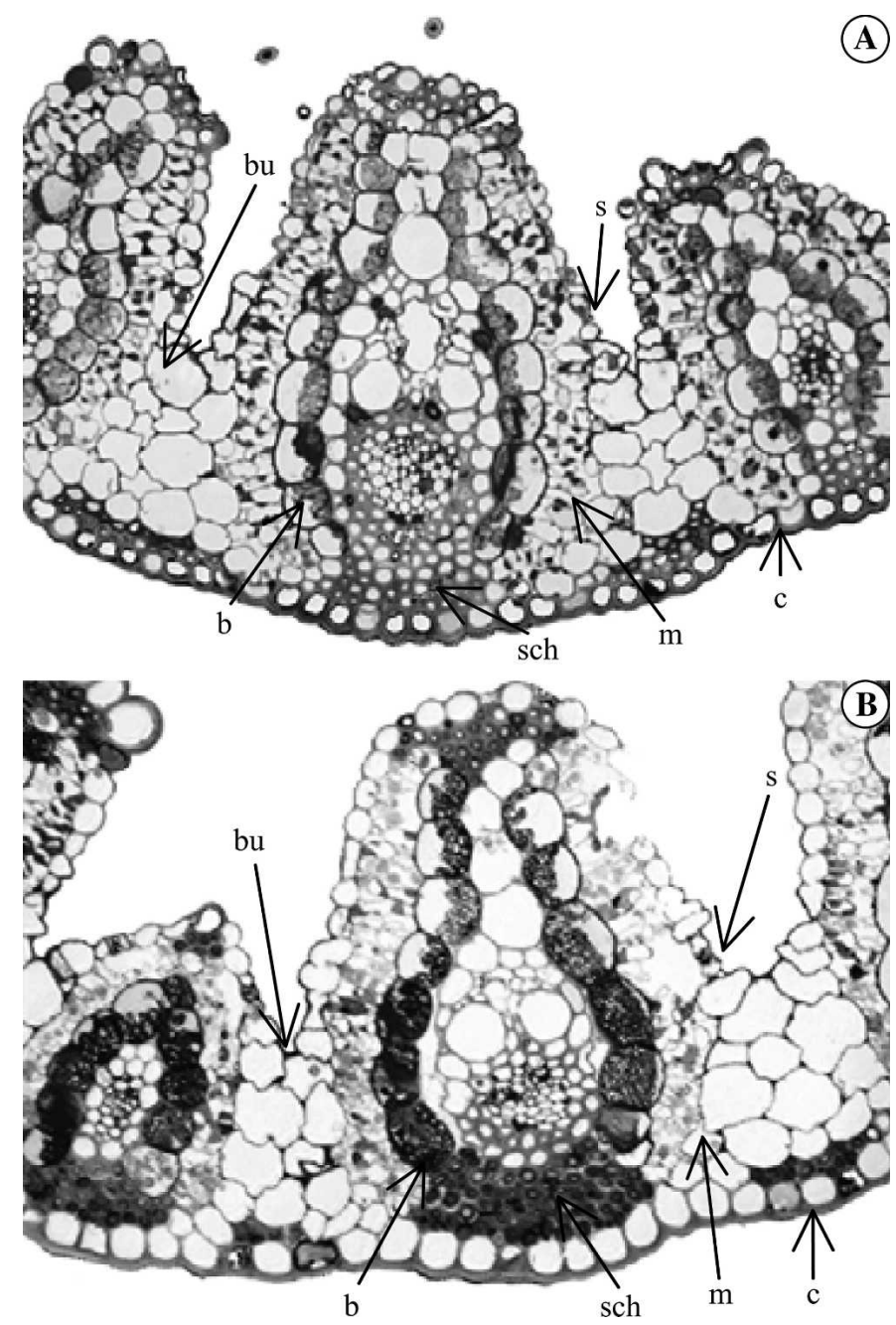

Fig. 3. Reference histological leaf sections of EK 11-1 (A) and EK 16-3 (B) sea oats genotypes after ex vitro acclimatization $(b=$ bundle sheath cell, $c=$ cuticle, $\mathrm{m}=$ mesophyll cell, $\mathrm{s}=$ stoma). 
3 Weeks
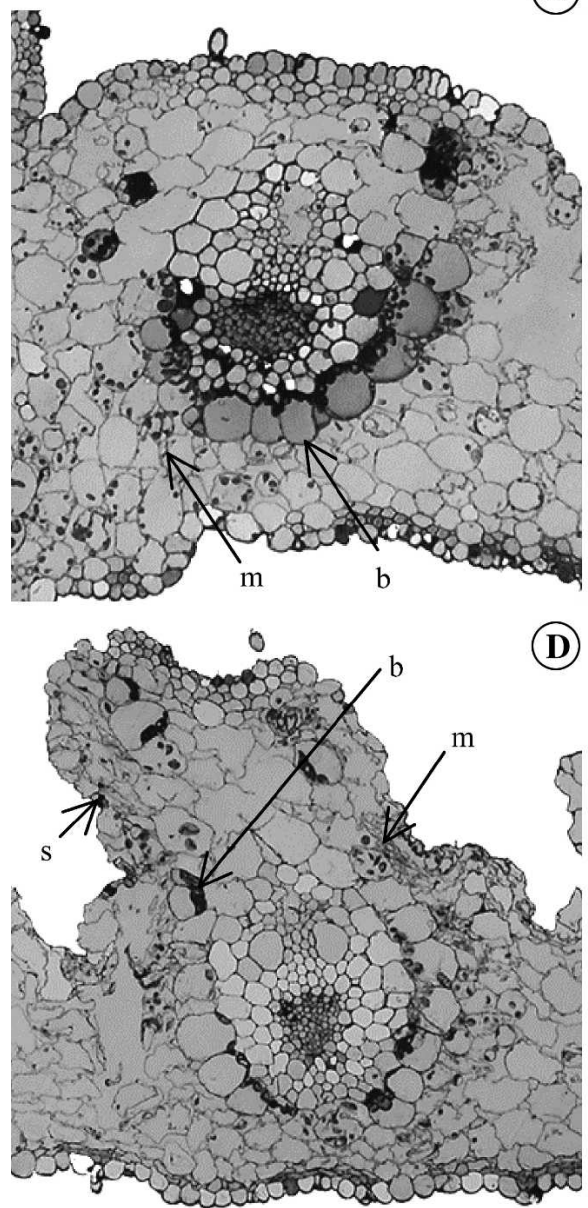

(D)
6 Weeks
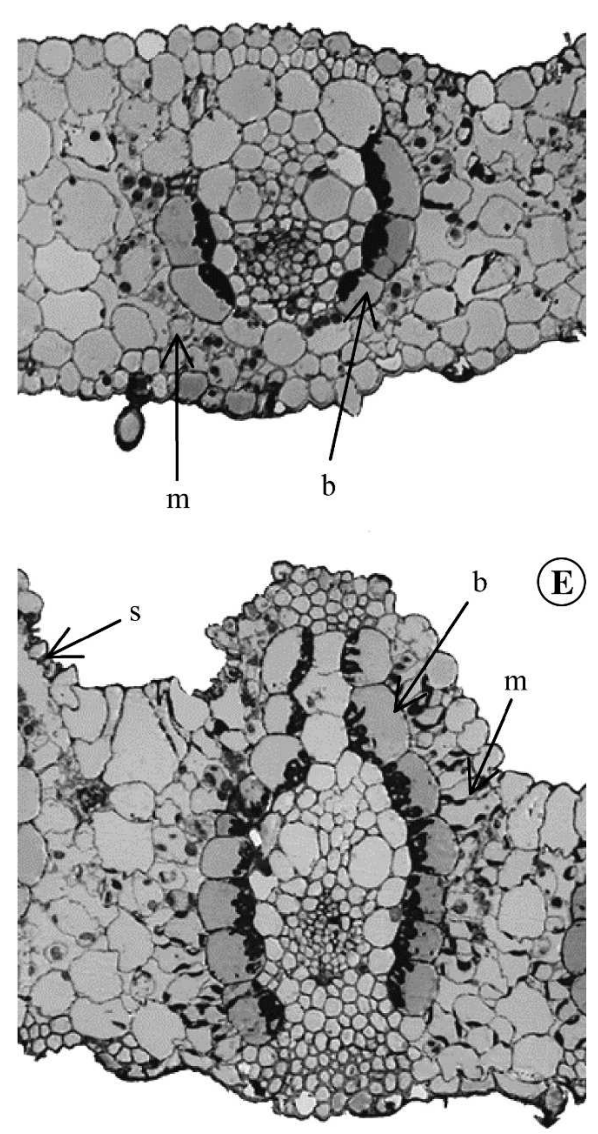

(B)
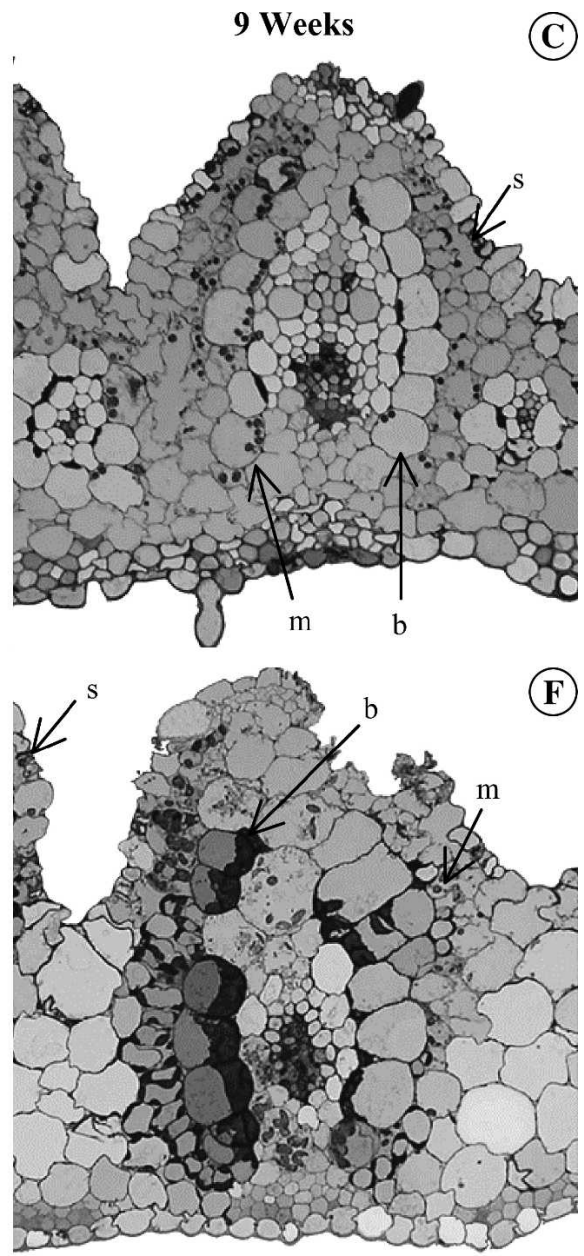

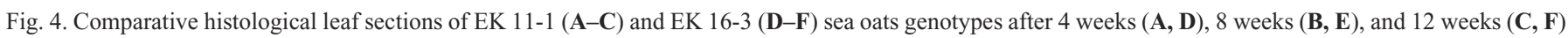
Stage II culture $(\mathrm{b}=$ bundle sheath cell, $\mathrm{m}=$ mesophyll cell, $\mathrm{s}=$ stoma $)$.

Bundle sheath cells of acclimatized plants were similar in shape between genotypes, contained larger chloroplasts than those of in vitro plantlets (Figs. 4 and 5), and were arranged centripetally in the bundle sheath. Schlerenchyma tissue was clearly present between the epidermal layers and the vascular bundles. A visible cuticle was present over the abaxial epidermis of both genotypes (bottom of the images). The adaxial epidermis (top of the images) of leaves contained bulliform cells. These cells were responsible for the epidermal foldings, which formed the characteristic adaxial ribs of the leaf blades. Multicellular glands were observed on both abaxial and adaxial surfaces.

Early in Stage II (Figs. 4A and 4D), large intercellular spaces in the mesophyll tissue of both genotypes were present. Both genotypes had mesophyll cells of varied sizes and shapes. At 8 weeks Stage II, these intercellular spaces were still present in EK 11-1 plantlets, whereas mesophyll of EK 16-3 leaves was more compact with fewer intercellular spaces. Compact mesophyll was present in both genotypes by 12 weeks Stage II. Production of adaxial ribs was only observed in EK 11-1 at 12 weeks Stage II culture. Adaxial ribs were present in EK 16-3 plantlets by 4 weeks Stage II. Furthermore, most vascular bundles of EK 16-3 leaves produced after 6 weeks Stage III were oval and completely occupied the leaf cross-section and filled the adaxial leaf ribs. Conversely, EK 11-1 plantlets lacked adaxial ribs during Weeks 4 and 8 and possessed vascular bundles that were round. During ex vitro conditions (Fig. 3), both genotypes exhibited a visible cuticle in the adaxial epidermis. However, the abaxial epidermis of both genotypes lacked a visible cuticle during Stage II (Fig. 4). Throughout Stage II culture, sclerenchyma tissue was present between the epidermal layers and the vascular bundles of EK 16-3 plantlets, whereas initial development of sclerenchyma tissue was only present at 12 weeks culture in EK 11-1 plantlets. Based on visual observations, mesophyll and bundle sheath cells of either genotype contained fewer numbers of chloroplasts than greenhouse-grown plants.

During Stage III culture, there were visible changes in leaf development in both genotypes that proved critical for successful acclimatization (Fig. 5). Intercellular spaces appeared to be as frequent as during Stage II. EK 16-3 leaves were comprised of a more compacted mesophyll than EK 11-1 plantlets and larger intercellular spaces. Furthermore, the mesophyll tissue in both genotypes was comprised of numerous small cells as compared with greenhouse-grown plants (Fig. 3). Both genotypes lacked adaxial ribs at 3 weeks' culture and exhibited large adaxial ribs at 6 and 9 weeks (Fig. 5). Vascular bundles were round in shape at 3 weeks (Figs. 5A and 5D) but became oval with time. At 6 weeks' culture, mesophyll and vascular bundles of EK 16-3 plantlets were highly structured (Fig. 5E) and similar to those of greenhouse plants (Fig. 3). However, these 
3 Weeks
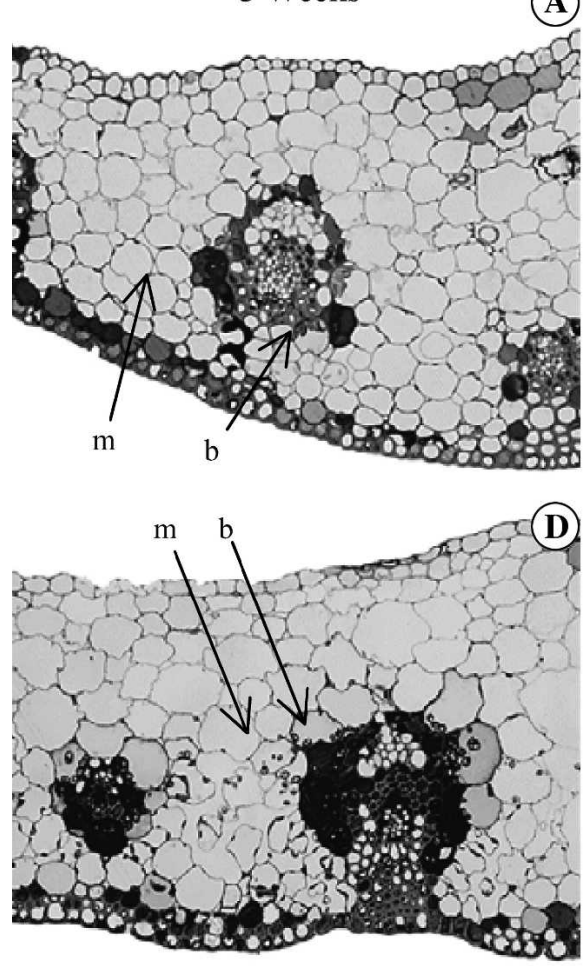

6 Weeks

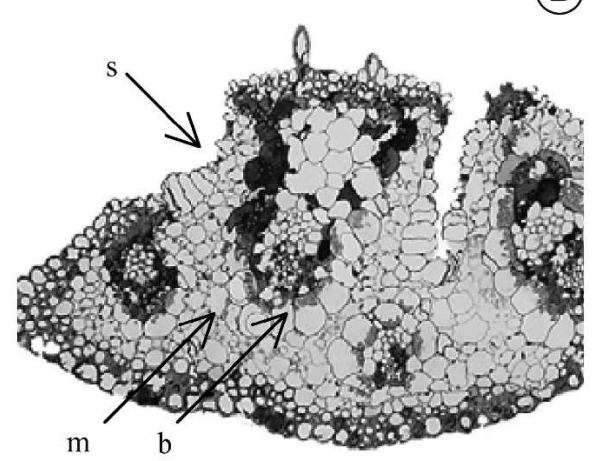

$\mathrm{m}$

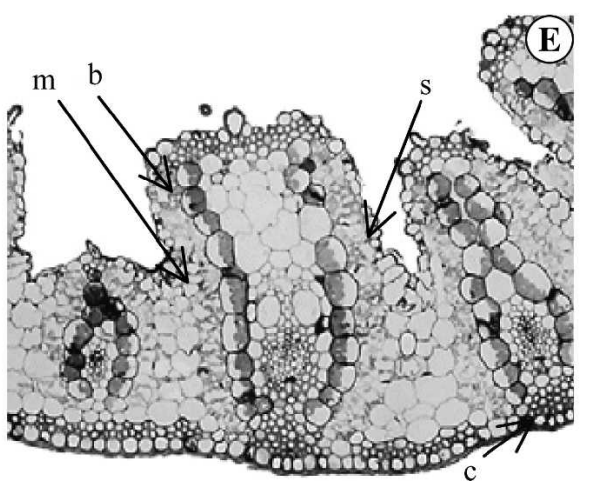

(B)
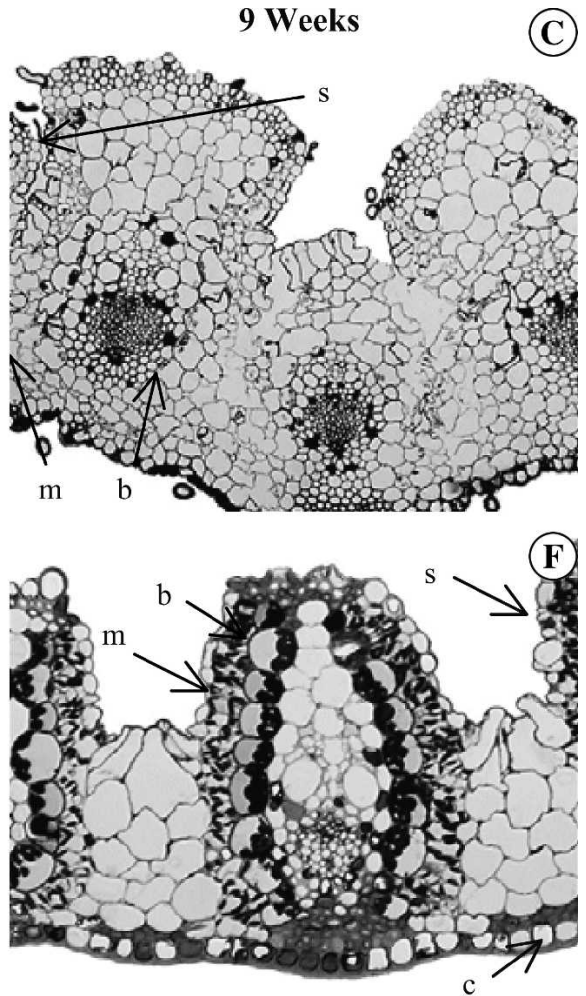

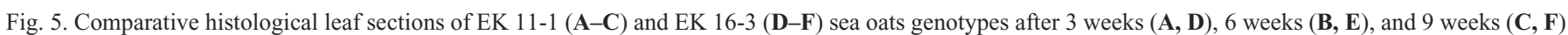
Stage III culture $(\mathrm{b}=$ bundle sheath cell, $\mathrm{c}=$ cuticle, $\mathrm{m}=$ mesophyll cell, $\mathrm{s}=$ stoma $)$.

structures were comparably disrupted and unorganized in EK 11-1 plantlets throughout Stage III (Fig. 5A-C). EK 16-3 plantlets possessed a visible cuticle over the abaxial epidermis at 6 and 9 weeks' culture (Fig. 5E-F) as opposed to EK 11-1 plantlets without visible cuticle throughout Stage III (Fig. 5AC). Sclerenchyma tissue between the epidermal layers and the vascular bundles was visible in EK 16-3 plantlets throughout Stage III (Fig. 5D-F), whereas it was less apparent in EK 11-1 plantlets and only visible after 6 weeks Stage III (Fig. 5B-C).

EK 16-3 leaves produced on plantlets cultured in Stage III for 6 to 9 weeks exhibited similar anatomical features to leaves produced on greenhouse-grown plants. Conversely, greater differences in tissue organization and anatomical features were observed between EK 11-1 leaves of Stage III plantlets and greenhouse-grown plants.

SCANNING ELECTRON MICROSCOPY. Leaf sections collected from acclimatized greenhouse-grown plants served as a reference (Fig. 6) for stomata comparisons with in vitro-produced plantlets (Figs. 7 and 8). Adaxial epidermal surface features (image not shown) and stomate morphology of greenhousegrown leaves were similar between both genotypes (Fig. 7). Both genotypes possessed glands on the adaxial ribs (image not shown). Stomata were found arranged in rows inside the invaginations of the adaxial leaf surfaces. Each row had one or two epidermal cells between the stomata in either genotype. Epidermal cells were raised, convex, and rectangular. A closer image of the stomata (Fig. 6) of both genotypes revealed significant epicuticular wax layer arranged in a homogeneous layer and bearing a crystalline structure. Stomata were characteristic of grass species with elongated guard cells surrounded by two large subsidiary cells and very small stomatal apertures.
Leaves were amphistomatous and, based on visual assessment, stomatal density was greater on the adaxial surface. Yet, because stomata were present in the invaginations of the adaxial epidermises, we were unable to accurately quantify stomatal density. Stomata were arranged in longitudinal rows of cells throughout the leaf blade length.

Similar to that observed in histological sections, leaves produced in Stage II exhibited no or relatively little wax deposition in both genotypes (Fig. 7A-D). Wax clusters were observed randomly over the leaf surfaces instead of in a homogeneous layer as in greenhouse plants. Stomatal apertures were fused or blocked with wax depositions regardless of being collected during the light or dark period (images not shown) during Stage II culture. Both genotypes exhibited similar stomatal structure and epidermal surface features regardless of Stage II duration.

During Stage III culture (Fig. 8A-D), increased wax deposition was observed on the leaf surfaces on both sea oats genotypes, especially on EK 16-3 leaves after 9 weeks' culture. Wax deposition was more homogeneous in EK 16-3 than in EK 11-1 leaf surfaces. Although EK 11-1 stomatal apertures appeared blocked in most cases, clearly defined stomatal apertures without blockage were observed in EK 16-3 leaves. The stomatal structure was similar between genotypes regardless of Stage III duration.

Transmission ELECTRON MICROSCOPY. Ultrathin section examination of samples collected from EK 11-1 and EK 16-3 plants revealed additional details such as differences in chloroplast ultrastructure in both mesophyll and bundle sheath cells. Chloroplast ultrastructure in acclimatized plants was very different in mesophyll cells compared with bundle sheath cells 

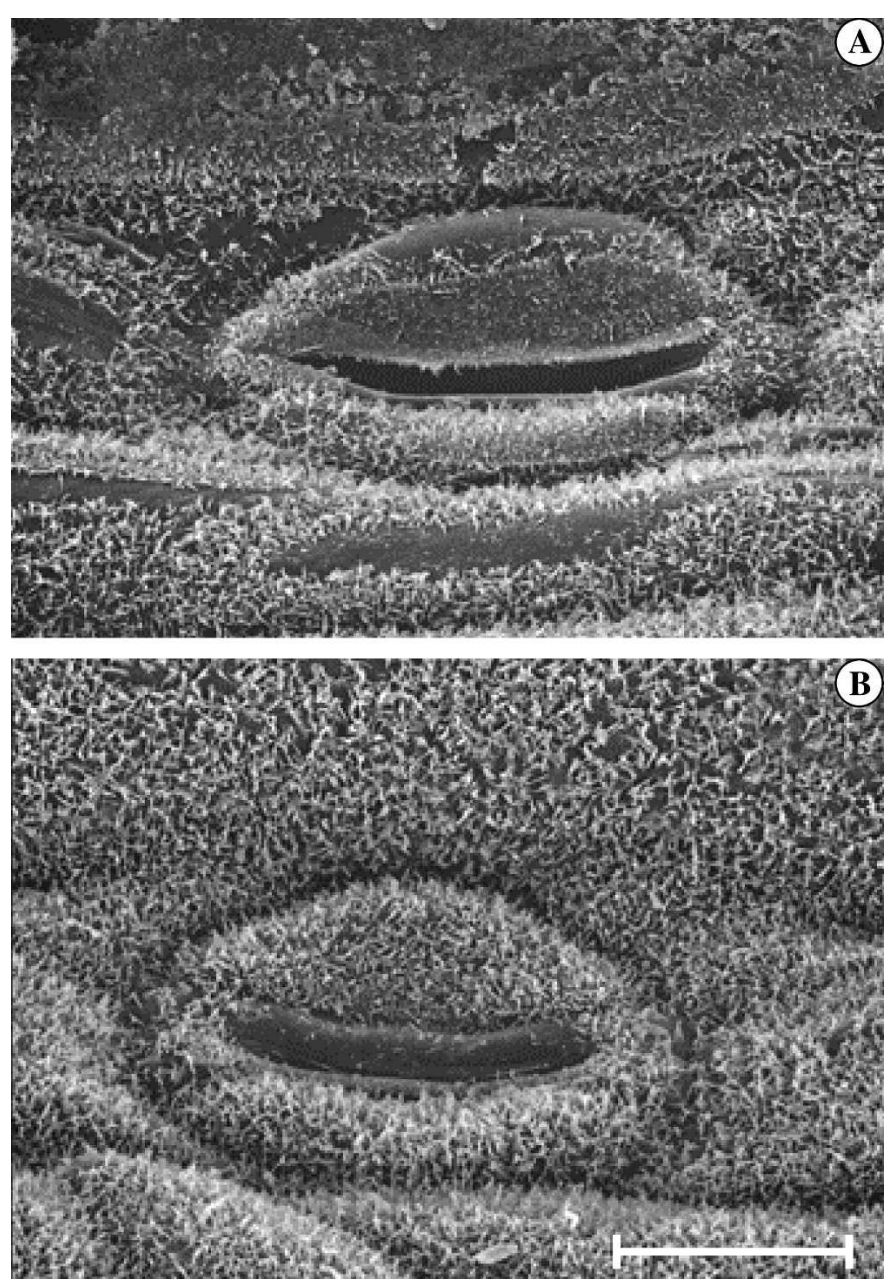

Fig. 6. Reference scanning electron microscopy of stomata on adaxial epidermis of EK 11-1 (A) and EK 16-3 (B) sea oats genotypes after acclimatization under Stage IV culture. Scale $=10 \mu \mathrm{m}$.

(Fig. 9). Both genotypes exhibited similar ultrastructural characteristics in ex vitro-produced leaves. Mesophyll cell chloroplasts (Figs. 9A and 9C) consisted of a highly compacted thylakoid membrane system with minimal stroma. A compact thylakoid membrane system was similarly observed in bundle sheath chloroplasts (Figs. 9B and 9D) and included large starch granules. Mesophyll cell chloroplasts were smaller and randomly arranged within the cells, whereas those in bundle sheath cells were larger and arranged centripetally within the bundle sheath.

Mesophyll cells of EK 11-1 Stage II plantlets contained chloroplasts with similar thylakoid membrane distribution at Weeks 4 and 8 (Fig. 10A-B); however, signs of senescence, including thylakoid disruption, were observed by 12 weeks Stage II (Fig. 10C). Similar signs of senescence were present after 12 weeks Stage II culture in EK 16-3 chloroplasts (Fig. 10I). Bundle sheath cells of either genotype contained chloroplasts that exhibited similar structural characteristics throughout Stage II culture. Although no visible starch granules were observed in chloroplasts of EK 11-1 plantlets (regardless culture duration), EK 16-3 chloroplasts of either cell type contained starch granules at 8 weeks Stage II.
During Stage III culture, EK 11-1 mesophyll cell chloroplasts contained swollen thylakoids at 6 and 9 weeks culture, whereas typical compacted thylakoid membranes were observed in EK 16-3 chloroplasts. Although large starch granules were only observed in the early weeks of Stage III in either genotype, smaller starch granules were observed after 6 weeks Stage III culture (Figs. 11D, 11E, and $11 \mathrm{~J})$.

\section{Discussion}

We observed differing responses between the two genotypes tested in vitro and especially during ex vitro acclimatization. Anatomical and morphological differences between genotypes were largely attributed to developmental plasticity in response to in vitro and ex vitro culture conditions (Majada et al., 2000). Culture duration during Stage II multiplication and Stage III rooting also had differing effects on acclimatization and survival of both genotypes to ex vitro conditions.

Anatomical observations indicated that unorganized tissues and abnormal anatomical features such as lack of cuticle, intercellular spaces in the mesophyll, blocked stomata, or disrupted chloroplast ultrastructure were common during Stage II for both genotypes, especially in the difficult-to-acclimatize genotype, EK 11-1. Additionally, SEM micrographs showed that both genotypes similarly lacked a homogeneous epicuticular wax layer and exhibited fused or blocked stomata during Stage II.

Transmission electron micrographs showed chloroplast disruption in both genotypes throughout Stage II. Lee et al. (1985) described similar chloroplast disruption as a characteristic of hyperhydric leaves. Furthermore, like hyperhydric leaves, Stage II sea oats leaves had lower chloroplast number with reduced thylakoid stacking compared with greenhousegrown plants (Jones et al., 1993).

Low light levels during culture result in swollen thylakoids in chloroplasts of certain plant species (Queralt, 1989). Similarly, under the low light intensity characteristic of Stage II, swollen thylakoids appeared more frequently in sea oats genotypes than when they were cultured under higher light intensity during Stage III. Frequently, swollen thylakoids occur after starch granules have accumulated within the chloroplast because starch is not exported during the dark period (Queralt, 1989). When plants use their stored reserves, starch is used but the thylakoid membranes remain swollen. Anatomical modifications caused by the tissue culture environment have a direct impact on diffusion of $\mathrm{CO}_{2}$ inside the in vitro-produced leaves and thus affect photosynthesis in vitro (Desjardins, 1995; Valero-Aracama et al., 2007). Alterations of the chloroplast ultrastructure are associated with disorganization of the lightharvesting pigments. As a result, photosynthetic capacity of developing leaves in vitro is low (Lee et al., 1985), causing poor acclimatization and survival ex vitro of Stage II plantlets. This state may contribute to the low ex vitro survival of sea oats Stage III microcuttings.

Another possible cause of mortality during acclimatization is poor control of water loss (Brainerd and Fuchigami, 1982). In angiosperms, this phenomenon has been related to poor stomatal functioning (Brainerd and Fuchigami, 1982) and reduced or abnormal structure of epicuticular wax (Grout and Aston, 1977). These characteristics were common in Stage II sea oats leaves. However, studies on transpiration rates of sea 
3 Weeks
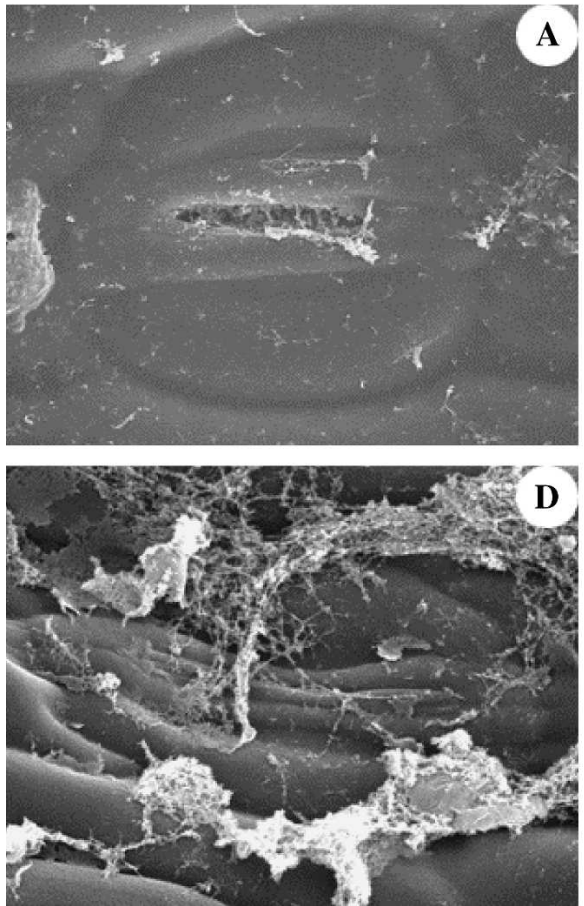

6 Weeks
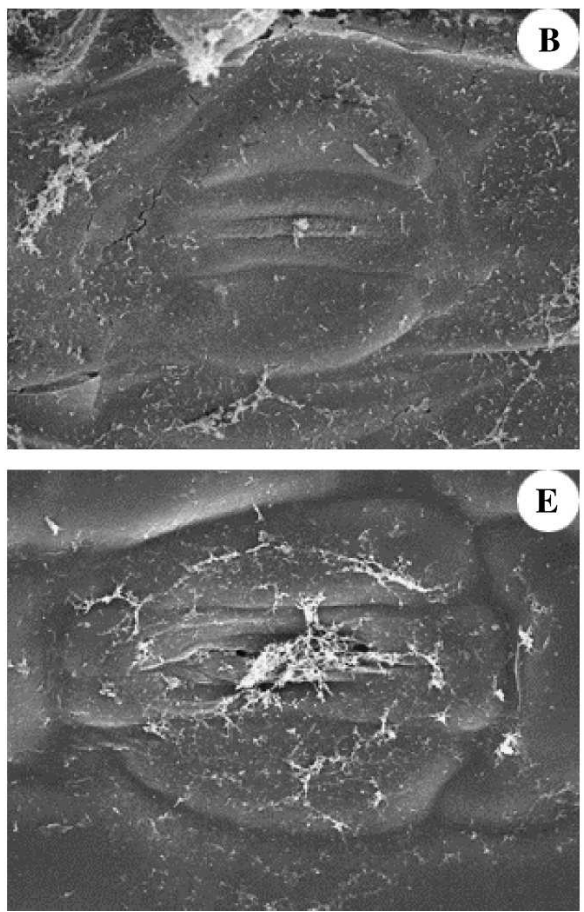

9 Weeks
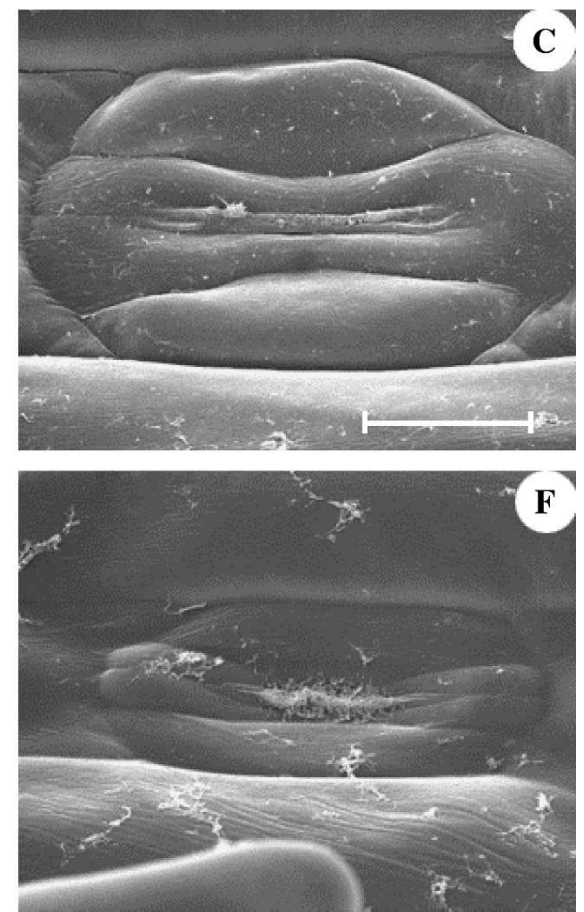

Fig. 7. Comparative scanning electron microscopy of stomata on adaxial epidermis of EK 11-1 (A-C) and EK 16-3 (D-F) sea oats (Uniola paniculata L.) genotypes after 4 weeks (left column), 8 weeks (center column), and 12 weeks (right column) Stage II culture. Scale $=10 \mu \mathrm{m}$.

\section{Weeks}
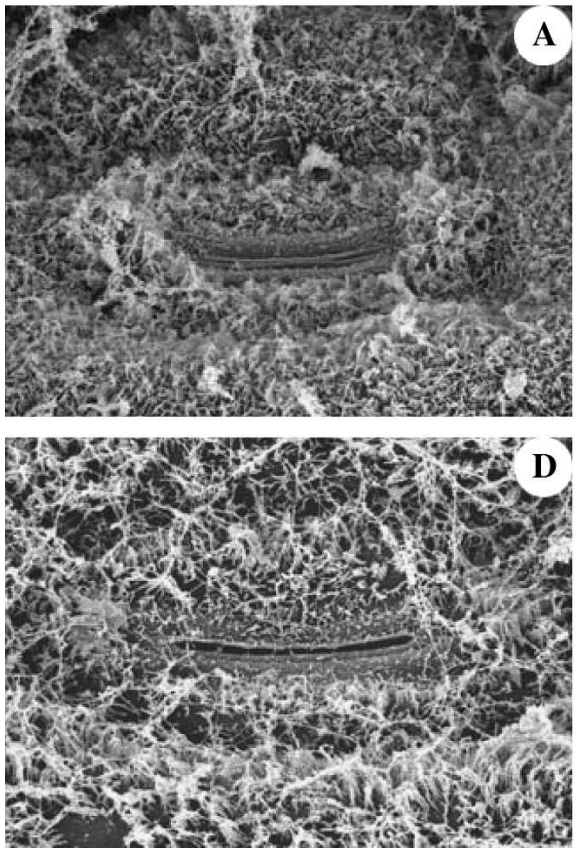

6 Weeks
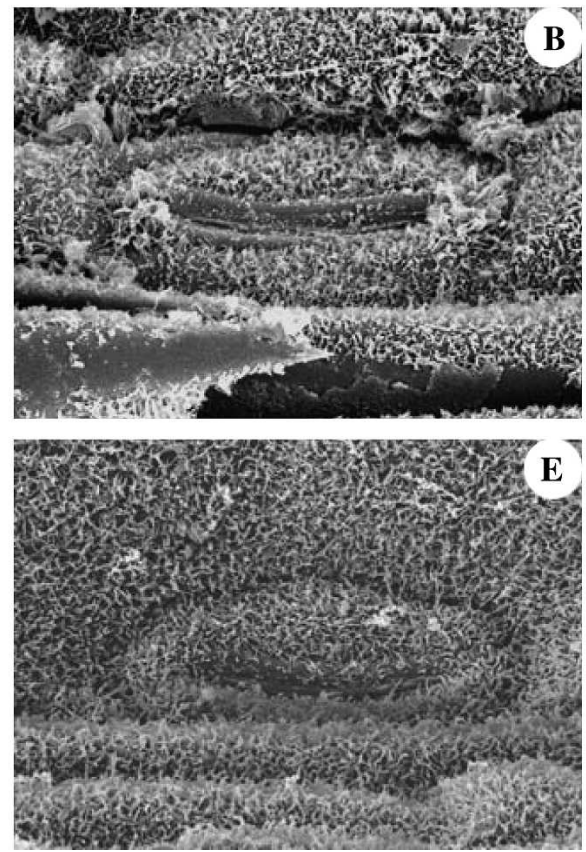

9 Weeks
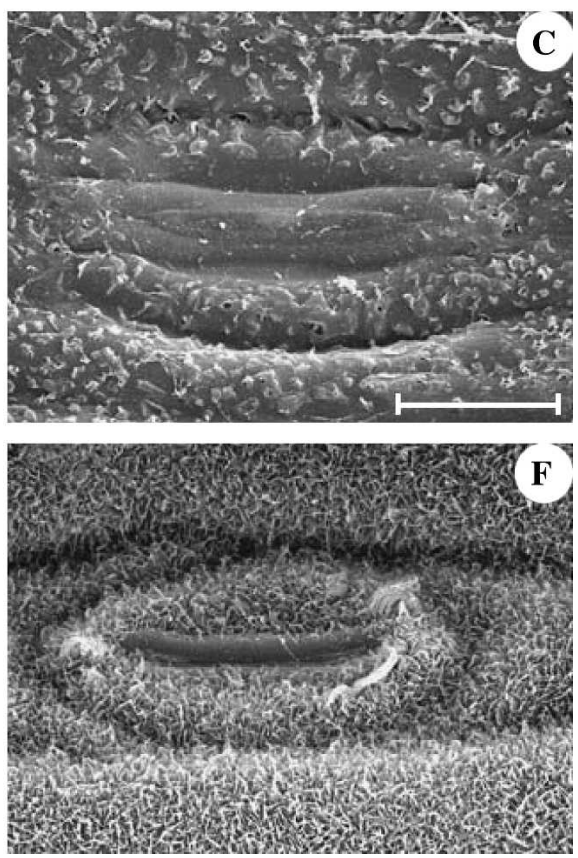

Fig. 8. Comparative scanning electron microscopy of stomata on adaxial epidermis of EK 11-1 (A-C) and EK 16-3 (D-F) sea oats genotypes after 3 weeks (left column), 6 weeks (center column), and 9 weeks (right column) Stage III culture. Scale $=10 \mu \mathrm{m}$.

oats at time of ex vitro transfer strongly indicated that this is not the main cause of poor survival ex vitro of EK 11-1 plants (Valero-Aracama et al., 2006).

To evaluate multiplication rates, we considered microcutting yield along with quality of shoots, including shoot biomass, leaf number, leaf length, and visual quality assessments. Our observations indicated that 8 weeks Stage II culture yielded the highest multiplication rates. After 8 weeks, multiplication rates decreased mainly because leaf senescence was extensive as a consequence of the translocation of nutrients and energy 

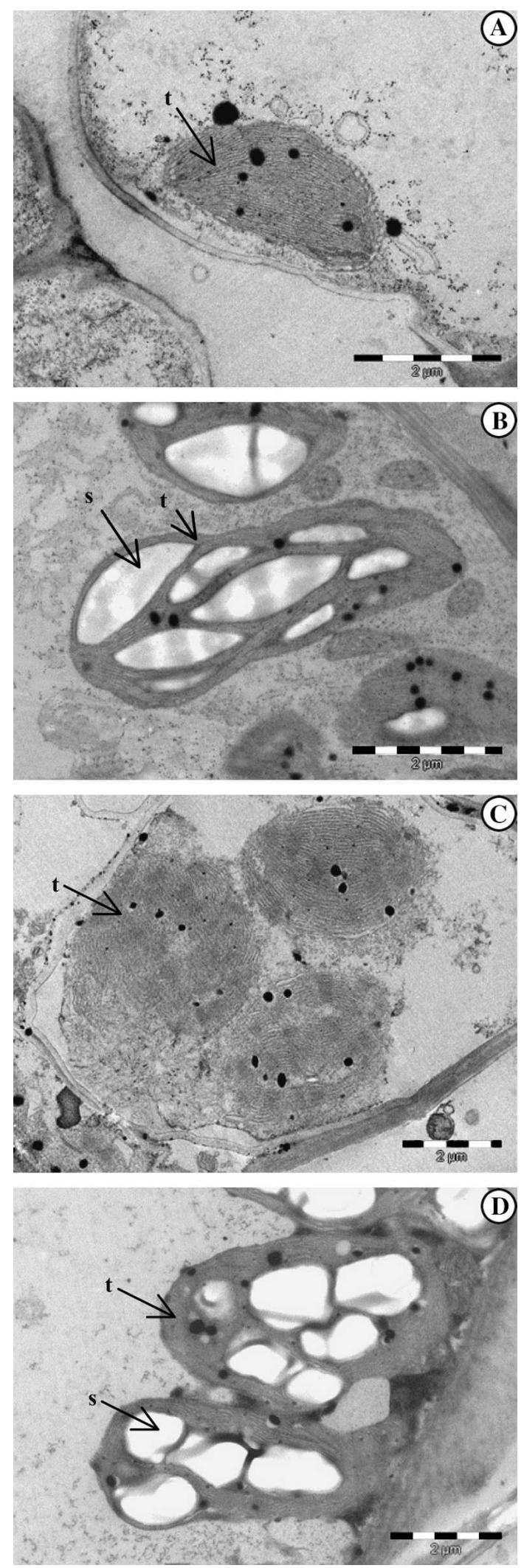

Fig. 9. Reference transmission electron microscopy of chloroplasts of EK 11-1 (A-B) and EK 16-3 (C-D) sea oats genotypes after acclimatization in mesophyll $(\mathbf{A}, \mathbf{C})$ and bundle sheath cells $(\mathbf{B}, \mathbf{D})$. Scale $=2 \mu \mathrm{m}(\mathrm{s}=\mathrm{starch}$ granule, $\mathrm{t}=$ thylakoid membranes). reserves to newly developing tissues at the expense of older tissues (Thomas and Sadras, 2001). During senescence, chloroplasts, proteins, and lipids are degraded and exported in the form of amino acids and sugars. As culture time increases, various conditional changes (such as BA concentration, secondary metabolite production, sugar content in the medium, and gas composition inside the vessel headspace), could cause the senescence of older leaves and the translocation of resources to new shoots or storage areas (Buchanan-Wollaston et al., 2003). Therefore, in a multiplication stage longer than 8 weeks, medium nutrient and sugar depletion could be limiting growth and multiplication of sea oats genotypes and induce leaf senescence.

During Stage III culture, shoot and root growth increased in both genotypes, but clear differences in plantlet morphology were observed between genotypes. After 6 weeks culture, EK 16-3 plantlets had greater shoot but lower root biomass than EK 11-1. Although energy sources were channeled mainly to root growth in EK 11-1, growth of elongated leaves with expanded leaf blades in EK 16-3 plantlets was predominant. These differences in developmental patterns are important during the transition from in vitro photomixotrophic or heterotrophic conditions to the ex vitro photoautotrophic conditions. During this transition, plantlets must adjust from using the sucrose supplied in the medium or their endogenous stored reserves to producing their own photoassimilates to continue growth and development ex vitro (Piqueras et al., 1998). Although the importance of photosynthetic capacity during acclimatization has been emphasized in many studies, Van Huylenbroeck and Debergh (1996) concluded that the photosynthetic ability at the time of ex vitro transfer is of secondary importance; the primary requirement is carbohydrate reserves that are large enough to overcome the transition to ex vitro conditions. However, in sea oats, photosynthetic capacity is also critical during acclimatization because in previous studies, we observed low ex vitro survival of EK 11-1 plants that exhibited high starch reserves at the time of ex vitro transfer (Valero-Aracama et al., 2006). Leaves in these plants were also short, thick, and without expanded blades, and plants also had large root systems.

One significant difference between the easy- and difficult-toacclimatize genotype is the ability of the former to produce leaves during Stage III of similar morphology and anatomical features as ex vitro-produced leaves. These features will allow for normal photosynthetic capacity when transferred ex vitro (Valero-Aracama et al., 2007). Optical light micrographs of leaves from EK 16-3 during Stage III revealed similar leaf tissue organization between plantlets cultured for 6 weeks in Stage III and after being acclimatized to greenhouse conditions. After 6 and 9 weeks Stage III, tissues were highly organized in the easy-to-acclimatize genotype compared with the difficultto-acclimatize genotype. EK 11-1 leaf sections exhibited disorganized mesophyll tissue throughout Stage III. Likewise, whole leaf morphology, especially expanded blades, was similar between acclimatized plantlets and EK 16-3 plantlets cultured 6 or 9 weeks in Stage III. Conversely, EK 11-1 plantlets produced small, thin leaves throughout Stage III culture. Several studies have indicated that in vitro-produced leaves of some species were both functionally and structurally anomalous (Sutter, 1981). Leaves of cauliflower (Brassica oleracea L. var. botrytis L.) (Wardle et al., 1979) and apple (Malus L.) (Brainerd and Fuchigami, 1981) had reduced stomatal functioning as well as reduced photosynthetic capacity 
3 Weeks
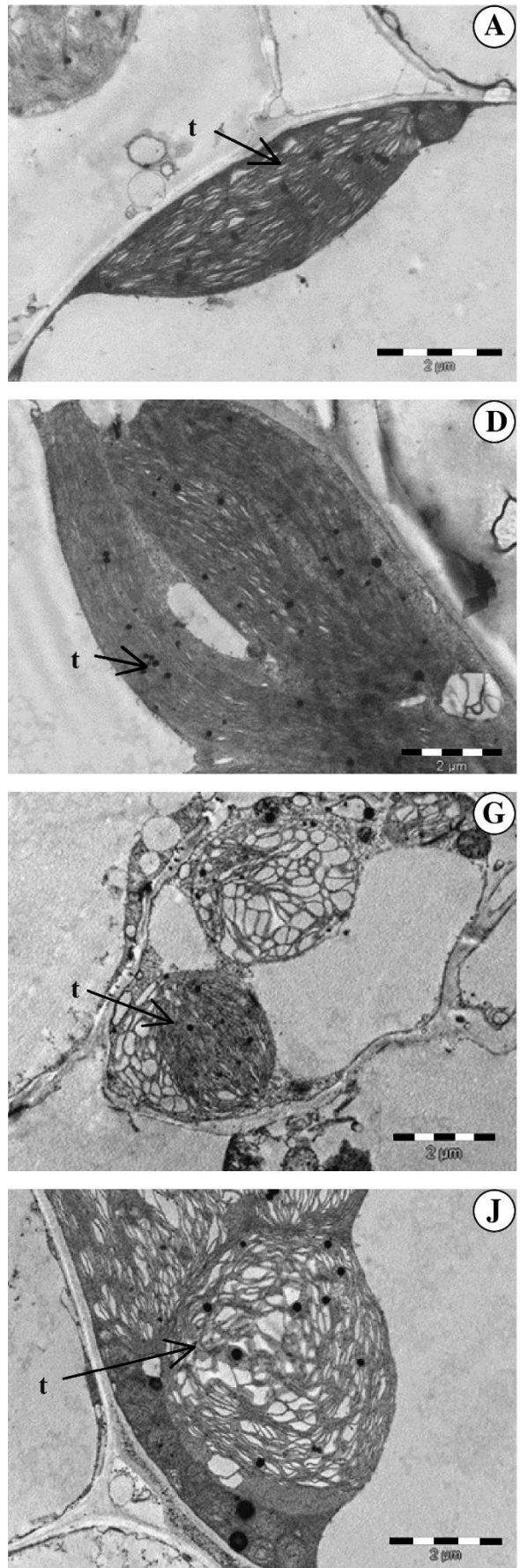

6 Weeks
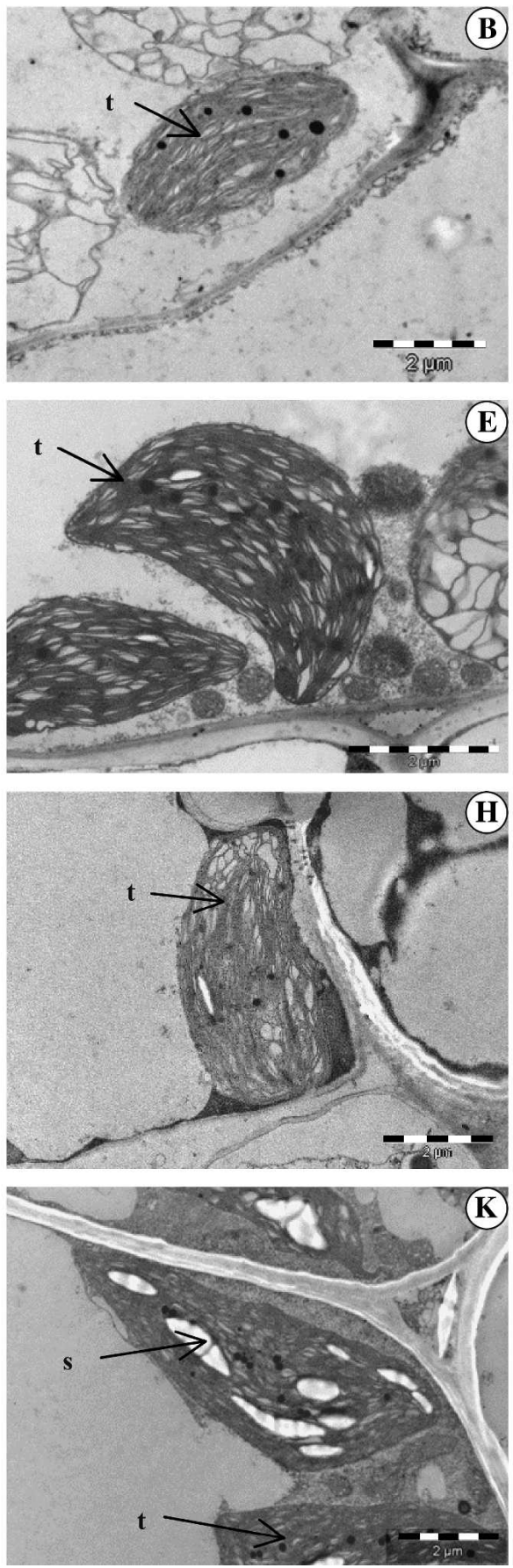

9 Weeks
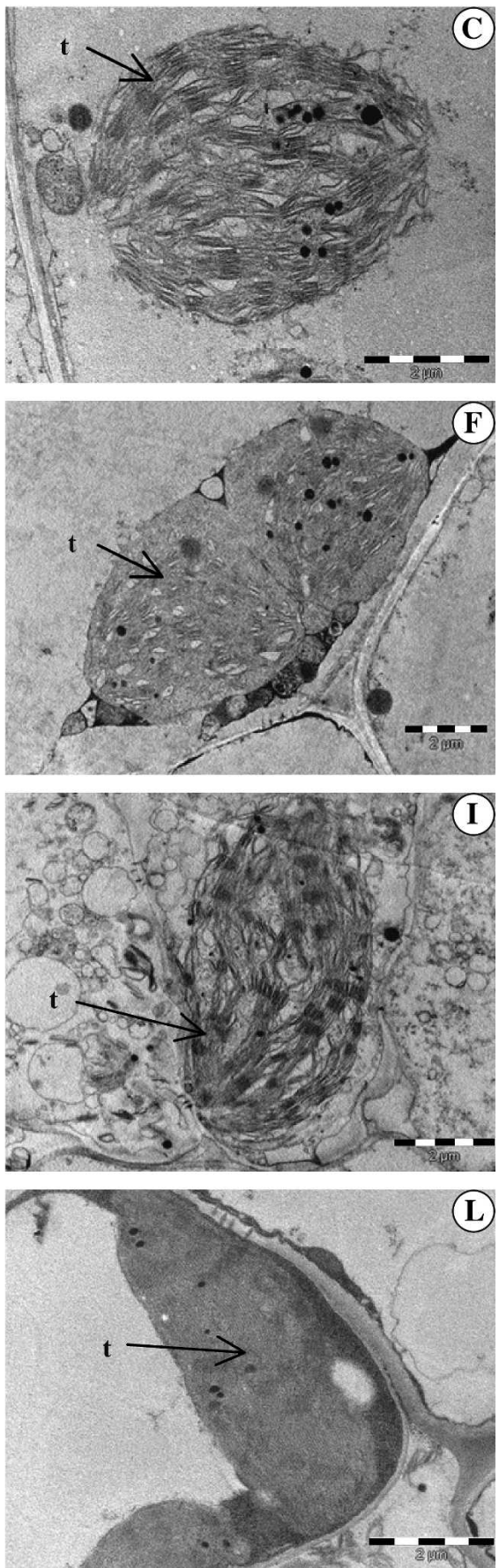

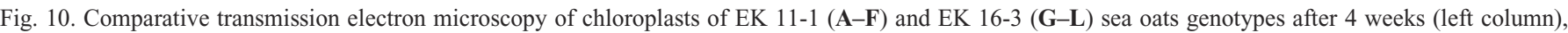
8 weeks (center column), and 12 weeks (right column) Stage II culture conditions in mesophyll (A-C and $\mathbf{G}-\mathbf{I})$ and bundle sheath cells $(\mathbf{D}-\mathbf{F}$ and $\mathbf{J}-\mathbf{L})$. Scale $=$ $2 \mu \mathrm{m}(\mathrm{s}=\mathrm{starch}$ granule, $\mathrm{t}=$ thylakoid membranes $)$.

(Grout and Aston, 1977) during in vitro culture. These leaves would be more susceptible to injury under the stress conditions characteristic during the change from in vitro to ex vitro culture.

Loss of photosynthetic capacity is suggested by decreased biomass during acclimatization. Loss in shoot dry weight (from 81 to $71 \mathrm{mg}$ ) was observed when EK 11-1 plantlets were transferred from 6 weeks Stage III to 4 weeks Stage IV. In contrast, EK 16-3 plantlets exhibited 2.7 times increase in shoot biomass (from 94 to $261 \mathrm{mg}$ ) at the same culture periods. After transfer ex vitro, a positive carbon balance is required for plantlet acclimatization and continued growth (Valero-Aracama et al., 2007). A positive carbon balance was not attained in EK 11-1 plantlets. The anomalous anatomy in EK 11-1 limited photosynthesis ex vitro resulting in decreased survival ex vitro and limited growth of those that survived. In addition, stored carbohydrate reserves were likely depleted before plants could produce sufficient photoassimilates to cope with the energy demands for growth (Valero-Aracama et al., 2006). 
3 Weeks
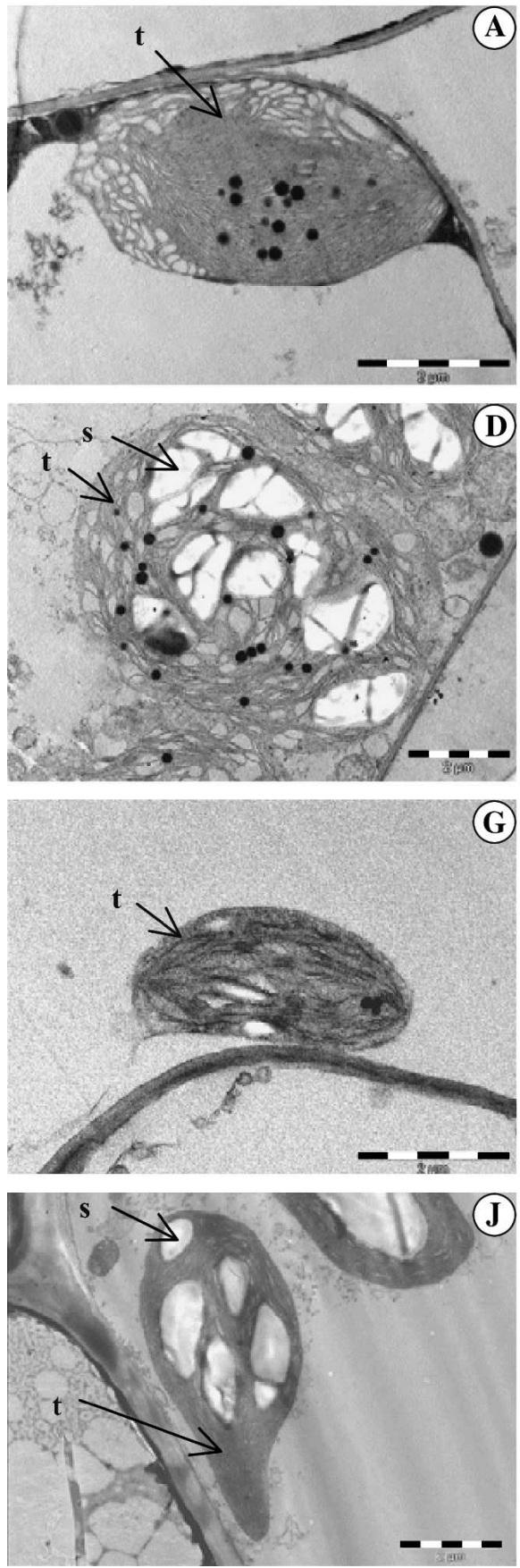

6 Weeks
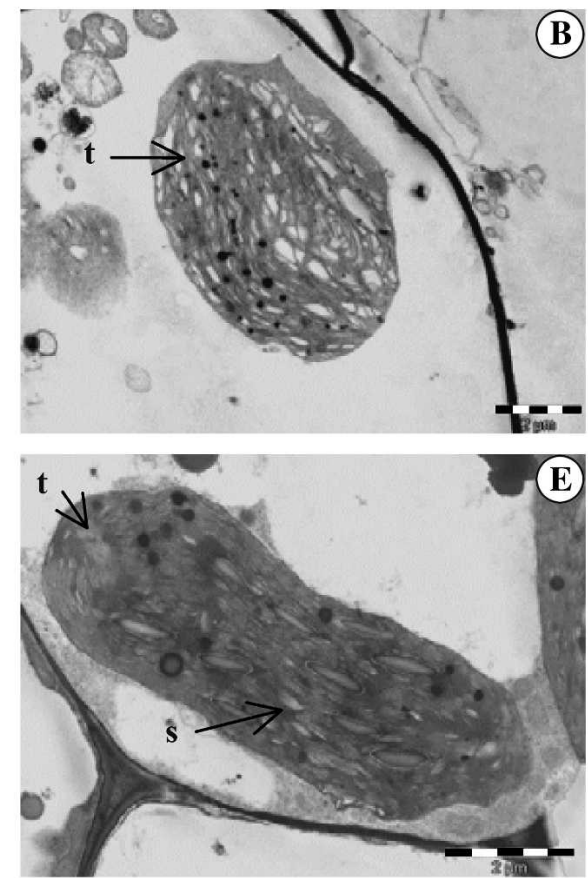

(H)
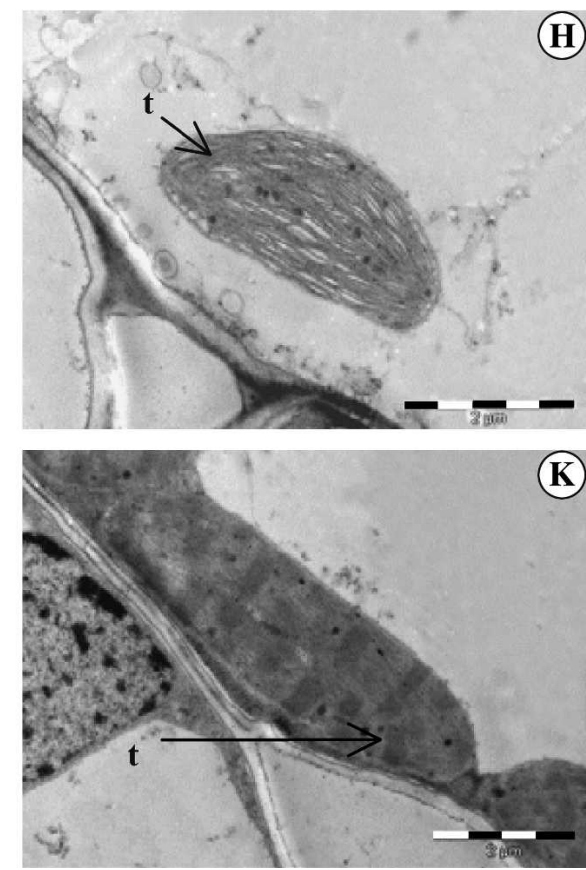

9 Weeks
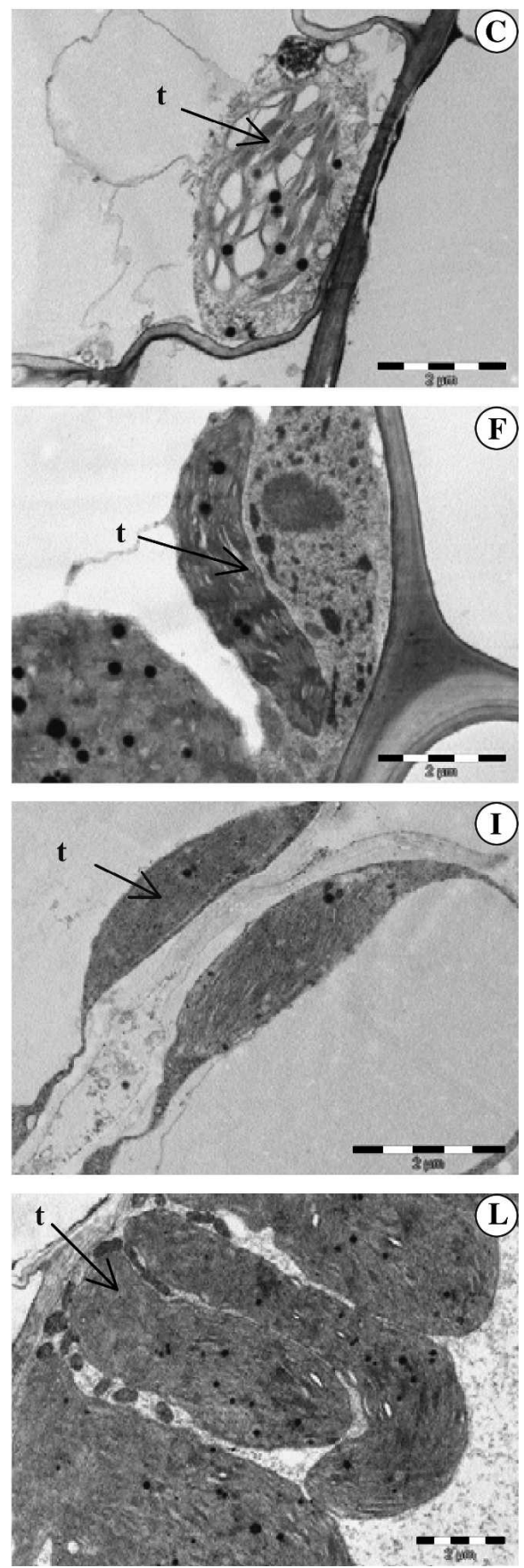

Fig. 11. Comparative transmission electron microscopy of chloroplasts of EK 11-1 (A-F) and EK 16-3 (G-L) sea oats genotypes after 3 weeks (left column), 6 weeks (center column), and 9 weeks (right column) Stage III culture in mesophyll (A-C and $\mathbf{G}-\mathbf{I})$ and bundle sheath cells $(\mathbf{D}-\mathbf{F}$ and $\mathbf{J}-\mathbf{L})$. Scale $=2 \mu \mathrm{m}(\mathrm{s}=\mathrm{starch}$ granule, $\mathrm{t}=$ thylakoid membranes).

Although adventitious root formation was necessary to increase ex vitro survival of both sea oats genotypes, excessive root biomass may have rendered EK 11-1 plants disadvantaged during acclimatization ex vitro. In sea oats, large root systems are sources of starch reserves and carbohydrates accumulated in vitro (Valero-Aracama et al., 2006). However, being composed of heterotrophic tissue, the roots often have high energy demands.

In vitro-produced roots of sea oats genotypes differed significantly in architecture and morphology. Several investigations have indicated that adventitious roots of various plant species formed in vitro display particular anatomical and morphological features induced by the physical characteristics of the gelled culture medium (McClelland et al., 1990). Therefore, the roots produced in vitro may promote growth in vitro but may not be functional after ex vitro transfer (McClelland et al., 1990).

During the initial acclimatization period, the fraction of dry matter allocated to roots has been reported to be small or unchanged (Fila et al., 1998). When comparing in vitro and ex vitro root dry weights of plants cultured for 6 weeks in Stage III 
and 4 weeks in Stage IV, we observed a decrease in root biomass of EK 11-1 plantlets from 52 to $31 \mathrm{mg}$ per plantlet, whereas there was an increase from 40 to $70 \mathrm{mg}$ in EK 16-3 plantlets. The decrease of EK 11-1 root biomass indicated that in vitro-formed roots were not fully functional and partially or totally died when transferred ex vitro. Conversely, the increase of EK 16-3 root biomass ex vitro indicated that those roots formed in vitro were possibly functional and continued growing after ex vitro transfer. High energy demands by roots, possibly limited root functionality and photosynthetic capacity of shoots in EK 11-1 plants, contribute to root senescence (ValeroAracama et al., 2006).

\section{Conclusions}

The abnormal anatomy and morphology of difficult-toacclimatize sea oats genotypes in vitro correlated with poor survival and acclimatization ex vitro. In vitro-produced sea oats require the formation of elongated leaves with expanded lamina and highly organized leaf tissues for successful acclimatization. These anatomical and morphological characteristics possibly facilitate the transition from photomixotrophic or heterotrophic conditions to photoautotrophic conditions by improving the control of water loss and the photosynthetic capacity ex vitro. We have reported a positive correlation in sea oats genotypes between levels of photoassimilates at time of ex vitro transfer and ex vitro survival (Valero-Aracama et al., 2006). Additionally, formation of roots in vitro appeared critical for survival ex vitro as a result of 1) increased water uptake ex vitro; and 2) reduced energy demands to produce roots ex vitro because this energy is supplied in vitro (Stage III). Furthermore, the Stage II duration should last at least 8 weeks to obtain morphological and anatomical features that will result in high survival rates ex vitro. An additional 4 weeks of culture results in increased senescence and therefore decreases the production efficiency.

During Stage III, sea oats plantlets require at least 6 weeks culture to produce elongated shoots and roots. Based on our earlier studies (Valero-Aracama et al., 2006, 2007), this stage is critical for the development of photosynthetic capacity and to accumulate carbohydrate reserves. The high survival observed in these plants indicated that their carbon balance was positive after acclimatization. Conversely, the difficult-to-acclimatize genotype exhibited poor development of shoots and an extensive heterotrophic root system that likely resulted in a negative carbon balance ex vitro, thus leading to low survival.

\section{Literature Cited}

Bachman, G.R. and T. Whitwell. 1995. Nursery production of Uniola paniculata. HortTechnology 5:295-298.

Brainerd, K.E. and L.H. Fuchigami. 1981. Acclimatization of aseptically cultured apple plants to low relative humidity. J. Amer. Soc. Hort. Sci. 106:515-518.

Brainerd, K.E. and L.H. Fuchigami. 1982. Stomatal functioning of in vitro and greenhouse apple leaves in darkness, mannitol, ABA, and $\mathrm{CO}_{2}$. J. Expt. Bot. 33:388-392.

Buchanan-Wollaston, V., S. Earl, E. Harrison, E. Mathas, S. Narabpour, T. Page, and D. Pink. 2003. The molecular analysis of leaf senescence-A genomics approach. Plant Biotechnol. J. 1: $3-22$.

Debergh, P.C. and R.H. Zimmerman. 1991. Micropropagation: Technology and application. Kluwer Academic Publishers, Dordrecht, The Netherlands.
Desjardins, Y. 1995. Photosynthesis in vitro-On the factors regulating $\mathrm{CO}_{2}$ assimilation in micropropagation systems. Acta Hort. 393:45-57.

Fila, G., J. Ghashghaie, J. Hoarau, and G. Cornic. 1998. Photosynthesis, leaf conductance and water relations of in vitro cultured grapevine rootstock in relation to acclimatization. Physiol. Plant. 102:411-418.

Grout, B.W.W. and M.J. Aston. 1977. Transplanting of cauliflower plants regenerated from meristem culture. I. Water loss and water transfer related to changes in leaf wax and to xylem regeneration. Hort. Res. 17:1-7.

Grout, B.W.W. and M.J. Aston. 1978. Transplanting of cauliflower plants regenerated from meristem culture. II. Carbon dioxide fixation and the development of photosynthetic ability. Hort. Res. 17:65-71.

Jones, N.B., P.M. Drennan, and J. van Staden. 1993. Leaf anatomy, chloroplast organization and photosynthetic rate of hyperhydric Eucalyptus saligna Sm. material. S. Afr. J. Bot. 59:551-555.

Kozai, T., K. Fujiwara, H. Hayashi, and J. Aitken-Christie. 1992. The in vitro environment and its control in micropropagation, p. 247-282. In: Kurata, K. and T. Kozai (eds.). Transplant production systems. Kluwer Academic Publishers, Dordrecht, The Netherlands.

Lee, N., H.Y. Wetzstein, and H.E. Sommer. 1985. Effect of quantum flux density on photosynthesis and chloroplast ultrastructure in tissue-cultured plantlets and seedlings of Liquidambar styraciflua L. towards improved acclimatization and field survival. Plant Physiol. 78:637-641.

Llorente, B.E. and N.M. Apóstolo. 1998. Effect of different growth regulators and genotype on in vitro propagation of jojoba. N. Z. J. Crop Hort. Sci. 26:55-62.

Majada, J.P., F. Tadeo, M.A. Fal, and R. Sánchez-Tamés. 2000. Impact of culture vessel ventilation on the anatomy and morphology of micropropagated carnation. Plant Cell Tissue Organ Cult. 63:207214.

McClelland, M.T., M.A.L. Smith, and Z.B. Carothers. 1990. The effects of in vitro and ex vitro root initiation on subsequent microcutting root quality in three woody plants. Plant Cell Tissue Organ Cult. 23:115-123.

McDowell, E.M. and B.F. Trump. 1976. Histological fixatives suitable for diagnostic light and electron microscopy. Arch. Pathol. Lab. Med. 100:405-414.

Murashige, T. and F. Skoog. 1962. A revised medium for rapid growth and bioassays with tobacco tissue cultures. Physiol. Plant. 15:473497.

Philman, N.L. and M.E. Kane. 1994. Micropropagation of Uniola paniculata L. (sea oats) from tiller explants. HortScience 29:559 (abstr.).

Piqueras, A., J.M. Van Huylenbroeck, B.H. Han, and P.C. Debergh. 1998. Carbohydrate partitioning and metabolism during acclimatization of micropropagated Calathea. Plant Growth Regulat. 26:25-31.

Queralt, M.C. 1989. Histological and ecophysiological study of the changes occurring during the acclimatization of in vitro cultured roses. State Univ., Gent, Belgium. PhD Thesis.

Ranamukhaarachchi, D.G. 2000. Molecular analysis of genetic diversity in Florida sea-oats (Uniola paniculata) populations: New approaches to generate and analyze molecular data. Univ. Florida, Gainesville, FL. PhD Diss.

Reynolds, E.S. 1963. The use of lead citrate at high $\mathrm{pH}$ as an electron opaque stain for electron microscopy. J. Cell Biol. 17:208-213.

Serret, M.D. and M.I. Trillas. 2000. Effects of light and sucrose levels on the anatomy, ultrastructure, and photosynthesis of Gardenia jasminoides Ellis leaflets cultured in vitro. Int. J. Plant Sci. 161:281-289.

Spurr, A.R. 1969. A low-viscosity epoxy resin embedding medium for electron microscopy. J. Ultrastruct. Res. 26:31-43.

Sutter, E. 1981. Problems posed by microplants morphology. Comb. Proc. Intl. Plant Prop. Soc. 31:563-566.

Thomas, H. and V.O. Sadras. 2001. The capture and gratuitous disposal of resources by plants. Funct. Ecol. 15:3-12. 
Valero-Aracama, C., M.E. Kane, S.B. Wilson, J.C. Vu, J. Anderson, and N.L. Philman. 2006. Photosynthetic and carbohydrate status of easy- and difficult-to-acclimatize sea oats (Uniola paniculata L.) genotypes during in vitro culture and ex vitro acclimatization. In Vitro Cell. Dev. Biol. Plant 42:572583.

Valero-Aracama, C., S.B. Wilson, M.E. Kane, and N.L. Philman. 2007. Influence of in vitro growth conditions on in vitro and ex vitro photosynthetic rates of easy- and difficult-to-acclimatize sea oats (Uniola paniculata L.) genotypes. In Vitro Cell. Dev. Biol. Plant 43:237-246.

Van Huylenbroeck, J. and P.C. Debergh. 1996. Impact of sugar concentration in vitro on photosynthesis and carbon metabolism during ex vitro acclimatization of Spathiphyllum plantlets. Physiol. Plant. 96:298-304.

Wardle, K., A. Quinlan, and I. Simpkins. 1979. Abscisic acid and the regulation of water loss in plantlets of Brassica oleracea L. regenerated through apical meristem culture. Ann. Bot. (Lond.) 43:745-752.

Woodhouse, W.W., Jr. 1982. Coastal sand dunes of the U.S., p. 1-44. In: Lewis, R. (ed.). Creation and restoration of coastal plant communities. CRC Press, Boca Raton, FL.

Ziv, M. 1991. Vitrification: Morphological and physiological disorders of in vitro plants, p. 45-49. In: Debergh, P.C. and R.H. Zimmerman (eds.). Micropropagation: Technology and application. Kluwer Academic Publishers, Dordrecht, The Netherlands. 